\title{
The Absolute Photoionization Cross Section of the Mercapto Radical (SH) from Threshold up to $15.0 \mathrm{eV}$
}

\author{
Helgi Rafn Hrodmarsson ${ }^{\# *}$, Gustavo A. Garcia, Laurent Nahon \\ Synchrotron SOLEIL, L'Orme des Merisiers, St Aubin, BP 48, Gif sur Yvette, France \\ Jean-Christophe Loison \\ Institut des Sciences Moléculaires (ISM), CNRS, Univ. Bordeaux, 351 cours de la Libration, \\ Talence, 33400, France \\ Bérenger Gans \\ Institut des Sciences Moléculaires d'Orsay (ISMO), UMR 8214 CNRS, Univ. Paris-Sud, \\ Université Paris-Saclay, F-91405 Orsay Cedex, France
}

Total number of pages in manuscript: 21

Tables: 2

Figures: 6

Running head title, if needed:

*Correspondence should be addressed to:

Helgi Rafn Hrodmarsson

Phone (HRH office): (+36) (0) 629413569

E-mail 1: hrodmarsson@strw.leidenuniv.nl

E-mail 2 : hr.hrodmarsson@gmail.com

\#Present address:

Sackler Laboratory for Astrophysics, Leiden Observatory, Leiden University, PO Box 9513, NL-2300 RA Leiden, The Netherlands 


\begin{abstract}
We present the absolute photoionization cross-section of the mercapto radical, $\mathrm{SH}$, recorded from its first ionization energy at $10.4 \mathrm{eV}$ up to a photon energy of $15 \mathrm{eV}$. The absolute scale was calibrated at the fixed photon energy of $11.2 \mathrm{eV}$ using the known values of $\mathrm{H}_{2} \mathrm{~S}$ and $\mathrm{S}$ as references. $\mathrm{SH}$ and $\mathrm{S}$ were produced in a microwave discharge flow-tube reactor by hydrogen abstraction of the $\mathrm{H}_{2} \mathrm{~S}$ precursor. The measured photoionization cross-section of SH dramatically differs from the one currently employed to model the presence of this species in a number of astronomical environments, where SH along with its ionic counterpart $\mathrm{SH}^{+}$have been detected. The cation spectroscopy and fragmentation of $\mathrm{H}_{2} \mathrm{~S}, \mathrm{SH}$ and $\mathrm{S}$ in the $9.2-15.0 \mathrm{eV}$ energy range obtained using threshold photoelectron techniques is also presented and discussed in the context of existing literature.
\end{abstract}

\title{
1. INTRODUCTION
}

Sulfur is among the most abundant elements in the universe following hydrogen, helium, carbon, oxygen, and nitrogen. ${ }^{1}$ Out of the 204 molecules that have been detected in the interstellar medium so far, twenty three of them are sulfur-bearing species, nine of which have been detected in the last decade. ${ }^{2}$ The mercapto radical (SH) and its cation, sulfanylium, $\left(\mathrm{SH}^{+}\right)$ have both been detected in various astronomical environments, ${ }^{3-7}$ but the sulfur hydrides are fairly unusual among interstellar hydrides as none of the species $\mathrm{S}, \mathrm{SH}, \mathrm{S}^{+}, \mathrm{SH}^{+}$or $\mathrm{H}_{2} \mathrm{~S}^{+}$can undergo exothermic $\mathrm{H}$ atom abstraction with $\mathrm{H}_{2} \cdot{ }^{8}$ This observation makes these species good tracers of turbulent dissipation regions where gas temperatures are elevated and significant ionneutral drift is present. ${ }^{6,9} \mathrm{SH}^{+}$was, furthermore, observed to have a particularly high relative abundance in these objects in comparison with other interstellar sulfur species such as $\mathrm{H}_{2} \mathrm{~S}$, $\mathrm{SO}_{2}$, and $\mathrm{CS}^{4}$ and over 150 reactions involving $\mathrm{SH}$ and $\mathrm{SH}^{+}$are currently included in the KIDA database. ${ }^{10} \mathrm{SH}$ can be formed in space via tunneling reactions involving $\mathrm{H}_{2} \mathrm{~S}$ and $\mathrm{H}$ on ultracold grain surfaces ${ }^{11}$ or via barrierless hydrogen abstraction reactions between $\mathrm{S}$ and other hydrogenated molecules. ${ }^{10}$ Meanwhile, $\mathrm{SH}^{+}$can be directly formed from the reaction between vibrationally excited $\mathrm{H}_{2}\left(\mathrm{X}^{1} \Sigma_{\mathrm{g}}^{+}\left(v^{\prime \prime}>1\right)\right)$ and $\mathrm{S}^{+}$ions ${ }^{12}$ or the reaction between $\mathrm{H}_{2} \mathrm{~S}^{+}$and atomic H. ${ }^{13}$ The interstellar chemistry of sulfur has recently been reviewed for dark clouds, ${ }^{13}$ protoplanetary disks, ${ }^{14}$ hot cores and corinos, ${ }^{15}$ and pre-stellar cores. ${ }^{16}$ 
The spectroscopy and ultraviolet photodissociation dynamics involving the mercapto radical and the sulfanylium ion have been relatively well studied with a number of experimental techniques ${ }^{17-38}$ as well as computations. ${ }^{39-49}$ The first photoelectron spectrum (PES) of SH was recorded by Dunlavey et al. ${ }^{17}$ where $\mathrm{SH}$ was produced with the rapid reaction $\mathrm{F}+\mathrm{H}_{2} \mathrm{~S} \rightarrow \mathrm{SH}$ $+\mathrm{HF}$ and the products were ionized with a Helium lamp. Several products were observed on top of the SH radical but several spectroscopic features were assigned to the $\mathrm{X}^{3} \Sigma^{-}, \mathrm{a}^{1} \Delta, \mathrm{b}^{1} \Sigma^{+}$, $\mathrm{A}^{3} \Pi$ and c ${ }^{1} \Pi$ electronic states of the $\mathrm{SH}^{+}$ion. Rostas et al. reported emission spectra of $\mathrm{SH}^{+}$ which allowed the determination of equilibrium molecular constants of the $\mathrm{X}^{3} \Sigma^{-}$, and $\mathrm{A}$ ${ }^{3} \Pi$ states of $\mathrm{SH}^{+}$and $\mathrm{SD}^{+} .{ }^{19}$ The first threshold photoelectron spectrum (TPES) of $\mathrm{SH}^{+}$was recorded by Hsu et al. where $\mathrm{SH}$ was produced via photodissociating a $\mathrm{H}_{2} \mathrm{~S}$ parent in the UV (234-240 nm) and SH was ionized via two-photon excitation to high- $n$ Rydberg states, followed by pulsed-field ionization (PFI). ${ }^{27}$ The photoionization observables of $\mathrm{SH}$ and $\mathrm{S}$ such as the anisotropy parameter, $\beta$, and relative photoionization cross-sections were further studied. ${ }^{33}$

Information is much scarcer, however, when dealing with absolute photoabsorption or photoionization cross-sections, and even more so when radical species are involved. Nevertheless, these are critical data needed to model and understand the photodynamics involving these species. In astrochemistry, these are converted to photoabsorption/photoionization rates if the photon flux is known in a given region of space. By quantitatively constraining the rates of photoprocesses, other chemical and physical parameters can be more reliably obtained, thus facilitating how observations are interpreted. In a recent seminal paper, ${ }^{50}$ photoabsorption and photoionization cross sections of interstellar species were compiled and used to model wavelength-dependent lifetimes (process rates) of interstellar molecules, using measured and calculated cross sections from several different databanks. Therein, the photoionization cross section of SH was arbitrarily simulated by a Gaussian centered at $100 \mathrm{~nm}(12.4 \mathrm{eV})$ with a maximum of $5 \times 10^{-18} \mathrm{~cm}^{2}(5.0 \mathrm{Mb})$.

Recently, the photoionization cross sections of radicals have been successfully studied at the DESIRS beamline at Synchrotron SOLEIL, employing a microwave discharge-equipped flow-tube. ${ }^{51,52}$ The microwave discharge is used to create Fluorine atoms that react with Hydrogen-bearing parent molecules; abstracting $\mathrm{H}$ atoms to produce $\mathrm{HF}$ and the desired radical product. $^{53}$

In this paper we present data regarding the absolute photoionization cross section of the $\mathrm{SH}$ radical from threshold up to $15.0 \mathrm{eV}$, followed by the measured threshold photoelectron 
spectra (TPES) of $\mathrm{H}_{2} \mathrm{~S}$, the mercapto radical, $\mathrm{SH}$ and the $\mathrm{S}$ atom, and briefly discuss the astronomical implications of these measurements.

\section{METHODOLOGIES}

\subsection{Experimental set-up}

$\mathrm{S}$ atoms and $\mathrm{SH}$ radicals were produced by the following consecutive reactions inside the flowtube:

$$
\begin{array}{ll}
\mathrm{F}+\mathrm{H}_{2} \mathrm{~S} \rightarrow \mathrm{SH}+\mathrm{HF} & \Delta \mathrm{H}_{\mathrm{r}, 298 \mathrm{~K}}=-1.99 \mathrm{eV} \\
\mathrm{F}+\mathrm{SH} \rightarrow \mathrm{S}+\mathrm{HF} & \Delta \mathrm{H}_{\mathrm{r}, 298 \mathrm{~K}}=-2.22 \mathrm{eV}
\end{array}
$$

These reactions are both fast, barrier-less and exothermic ${ }^{54,55}$ and hence no isotopic effects are expected.

Experiments were performed on the DESIRS VUV undulator beamline ${ }^{56}$ located at the third generation French national synchrotron facility SOLEIL (Gif-sur-Yvette, France). The beamline provided linearly polarized light with a photon flux of $10^{12}-10^{13} \mathrm{ph} / \mathrm{s}$ over the VUV range and we used monochromator slits corresponding to a resolution of $6 \mathrm{meV}$ at $10 \mathrm{eV}$. Downstream the interaction region, a photodiode (AXUV, IRD) is used to measure the photon flux and correct energy dependent measurements.

Table 1. Experimental parameters relevant to the flow-tube through which optimal conditions were achieved to perform the photon energy scans as described in the text.

\begin{tabular}{|l|l|}
\hline Experimental parameters & Value \\
\hline $\mathrm{F}_{2} / \mathrm{He}$ mixture & $5 \% / 95 \%$ \\
\hline Total chamber pressure & 1 Torr \\
\hline Precursor flow speed & $10 \mathrm{sccm}$ (standard cubic centimeters per minute) \\
\hline Total flow speed & $1100 \mathrm{sccm}$ \\
\hline $\mathrm{F}$ atom concentration & $1.0-6.0 \times 10^{13}$ atom $/ \mathrm{cm}^{3}$ \\
\hline $\mathrm{H}_{2} \mathrm{~S}$ concentration & $2.0 \times 10^{14} \mathrm{molecule} / \mathrm{cm}^{3}$ \\
\hline
\end{tabular}

An $\mathrm{H}_{2} \mathrm{~S}$ canister was obtained commercially (Air Liquide, $\geq 99.5 \%$ purity) and the gas was directed into a flow-tube reactor where it mixed with Fluorine atoms that were produced by a MW discharge of a $5 \% \mathrm{~F}_{2}$ mixture diluted in He. The flow-tube was placed inside the permanent molecular beam end-station SAPHIRS ${ }^{57}$ and has been described in detail elsewhere. ${ }^{53}$ Several experiments have been carried out using the flow-tube where the physical 
parameters of the hydrogen abstraction are described in detail, ${ }^{53}$ hence only the most relevant parameters are tabulated here (see Table 1).

A gas filter upstream of the beamline monochromator was filled with Argon to filter out the higher harmonics from the undulator. Calibration of the energy scale was achieved by using autoionizing resonances corresponding to transitions in neutral atomic sulfur. ${ }^{58}$ The accuracy of the calibration is better than $2 \mathrm{meV}$ between 10.0 and $12.0 \mathrm{eV}$. However, above $12.0 \mathrm{eV}$ the energies of autoionizing resonances are only known with $3-5$ significant digits. This decreases the certainty of the calibration above $12.0 \mathrm{eV}$ and hence we report an energy calibration better than $6 \mathrm{meV}$ from $12.0 \mathrm{eV}$ up to $15.0 \mathrm{eV}$.

The double imaging photoelectron/photoion coincidence (i²PEPICO) spectrometer DELICIOUS3 ${ }^{59}$ was used to detect electrons and ions in coincidence with a velocity map imaging (VMI) setup and an imaging linear time-of-flight analyzer, respectively. The coincidence scheme yields mass-selected photoelectron images which are then converted into photoelectron spectra (PES) by Abel inversion. ${ }^{60}$ Hence, we obtained mass-tagged PES of all the flow-tube reaction products simultaneously.

Two different energy scans were performed. First, by scanning the photon energy in the $9.7-12.0 \mathrm{eV}$ range in $3 \mathrm{meV}$ steps, and second, in the $11.9-15.0 \mathrm{eV}$ range in $10 \mathrm{meV}$ steps, allowing for a scan overlap of approximately $0.1 \mathrm{eV}$. Particle acceleration was achieved with a DC field of $53 \mathrm{~V} \mathrm{~cm}^{-1}$ for the first scan while the field was increased to $176 \mathrm{~V} \mathrm{~cm}^{-1}$ for the second scan. In short, mass-selected photoelectron signals as a function of electron kinetic energy and photon energy were obtained for the flow-tube reaction products between 9.7 and $15.0 \mathrm{eV}$ which included and were not limited to $\mathrm{H}_{2} \mathrm{~S}, \mathrm{SH}, \mathrm{S}$, and $\mathrm{S}_{2}$. Results pertaining to the production of $\mathrm{S}_{2}$ will be the subject of a later publication. The data were further reduced to yield the mass-selected photoionization yields (integrating the signal over all photoelectron kinetic energies at each photon energy), and the mass-selected TPES with a $5 \mathrm{meV}$ electron resolution using a method described in previous works. ${ }^{61,62}$

\subsection{Isotopic correction of the ${ }^{32} \mathrm{SH}$ photoionization yield}

The natural abundances of the ${ }^{32} \mathrm{~S},{ }^{33} \mathrm{~S}$, and ${ }^{34} \mathrm{~S}$ sulfur isotopes are $94.99 \%, 0.75 \%$, and $4.25 \%$, respectively. As such, the ${ }^{33} \mathrm{~S},{ }^{34} \mathrm{~S}$, and ${ }^{33} \mathrm{SH}$ isotopologues had to be subtracted from the $\mathrm{m} / \mathrm{z}=$ $33 \mathrm{amu}$ and $\mathrm{m} / \mathrm{z}=34 \mathrm{amu}$ signals to obtain the uncontaminated ${ }^{32} \mathrm{SH}$ and $\mathrm{H}_{2}{ }^{32} \mathrm{~S}$ photoionization yields.

In the 32 amu channel of the total photoionization yields (see section 3.2 below), the appearance of metastable signals - arising from autoionization of metastable $\mathrm{S}\left({ }^{1} \mathrm{D}\right)$ atoms - 
provided us with a benchmark to subtract the corresponding metastable ${ }^{33} \mathrm{~S}$ signals from the $33 \mathrm{amu}$ ion yield to obtain the pure ${ }^{32} \mathrm{SH}$ photoionization yield. The $32 \mathrm{amu}$ spectrum arises from photoionization of ${ }^{32} \mathrm{~S}$ atoms and includes no other contributing sources, i.e. it is the pure photoionization spectrum of ${ }^{32} \mathrm{~S}$. We multiplied it by a factor which made it equal to the contribution of the ionized ${ }^{33} \mathrm{~S}$ metastable atoms in the $33 \mathrm{amu}$ spectrum and this allowed the ${ }^{33} \mathrm{~S}$ contribution to be effectively subtracted from the $33 \mathrm{amu}$ photoionization spectrum. The same procedure was then applied to the 34 amu photoionization spectrum with regards to the ${ }^{34} \mathrm{~S}$ contribution.

To obtain the pure $\mathrm{H}_{2}{ }^{32} \mathrm{~S}$ photoionization yield, the pure ${ }^{32} \mathrm{SH}$ photoionization yield (as obtained from the subtraction of ${ }^{33} \mathrm{~S}$ signals from the $33 \mathrm{amu}$ signal) was multiplied by a factor that was optimized so that the most prominent signals coming from the ${ }^{33} \mathrm{SH}$ isotopologue, e.g. the autoionizing resonances at $10.18 \mathrm{eV}$ and $10.83 \mathrm{eV}$ were effectively removed (see section $3.2)$.

The thresholds for dissociative ionization in $\mathrm{H}_{2} \mathrm{~S}$ to form $\mathrm{S}^{+}$and $\mathrm{SH}^{+}$are approximately $13.4 \mathrm{eV}$ and $14.3 \mathrm{eV}$, respectively. ${ }^{63}$ To compensate for the contributions to the $\mathrm{S}^{+}$and $\mathrm{SH}^{+}$ion yields from dissociative ionization of $\mathrm{H}_{2} \mathrm{~S}$, a scan was performed with the MW discharge off and the ion yields of SH and S were measured in relation to $\mathrm{H}_{2} \mathrm{~S}$, and subtracted from the scan where the discharge was turned on.

\subsection{Calculations}

Potential energy curves for $\mathrm{SH}^{+}$were calculated by using the internally contracted multireference configuration interaction method with Davidson correction (MRCI + Q) with complete active space self-consistent field (CASSCF) wave- functions. The CASSCF and MRCI calculations were performed at full valence, namely with 16 electrons distributed in 10 orbitals with the $1 \mathrm{~s}$ and $2 \mathrm{~s}$ orbitals of sulfur atoms kept doubly occupied but fully optimized. All calculations were performed using the MOLPRO 2012 package. ${ }^{64}$

\section{RESULTS AND DISCUSSION}

\subsection{Reactor composition / reaction products}

The mass spectrum obtained by integrating the ion TOF over the photon energy range $11.0-12.0 \mathrm{eV}$ is presented in Figure 1. The parent compound $\mathrm{H}_{2} \mathrm{~S}$ is visible with the $\mathrm{H}_{2}{ }^{32} \mathrm{~S}$, $\mathrm{H}_{2}{ }^{33} \mathrm{~S}$, and $\mathrm{H}_{2}{ }^{34} \mathrm{~S}$ isotopologues discernible, as well as the radical products, $\mathrm{SH}$ and $\mathrm{S}$. As the $\mathrm{H}_{2} \mathrm{~S}$ is used as a precursor, its signal is severely depleted which ultimately affected its recorded TPES (see section 3.3.1). The strongest signal, however, pertains to ${ }^{32} \mathrm{~S}_{2}$, which can form 
through recombination via the exothermic reactions ${ }^{32} \mathrm{~S}+{ }^{32} \mathrm{~S},{ }^{32} \mathrm{~S}+\mathrm{H}^{32} \mathrm{~S}$ or even ${ }^{32} \mathrm{~S}+\mathrm{F}^{32} \mathrm{~S} .{ }^{54}$ The ${ }^{32} \mathrm{~S}^{33} \mathrm{~S}$ and ${ }^{32} \mathrm{~S}^{34} \mathrm{~S}$ isotopologues are visible as well in abundances of $1.5 \%$ and $8.0 \%$ compared to that of ${ }^{32} \mathrm{~S}_{2}$ or approximately twice that of the natural abundances of the ${ }^{33} \mathrm{~S}$ and ${ }^{34} \mathrm{~S}$ isotopes as expected.

Other products / impurities are observed, most notably ${ }^{32} \mathrm{SO}$, but other extraneous species include $\mathrm{NS},{ }^{34} \mathrm{SO}, \mathrm{SF}, \mathrm{HSF}$ and ${ }^{32} \mathrm{~S}_{2} \mathrm{~F}$.

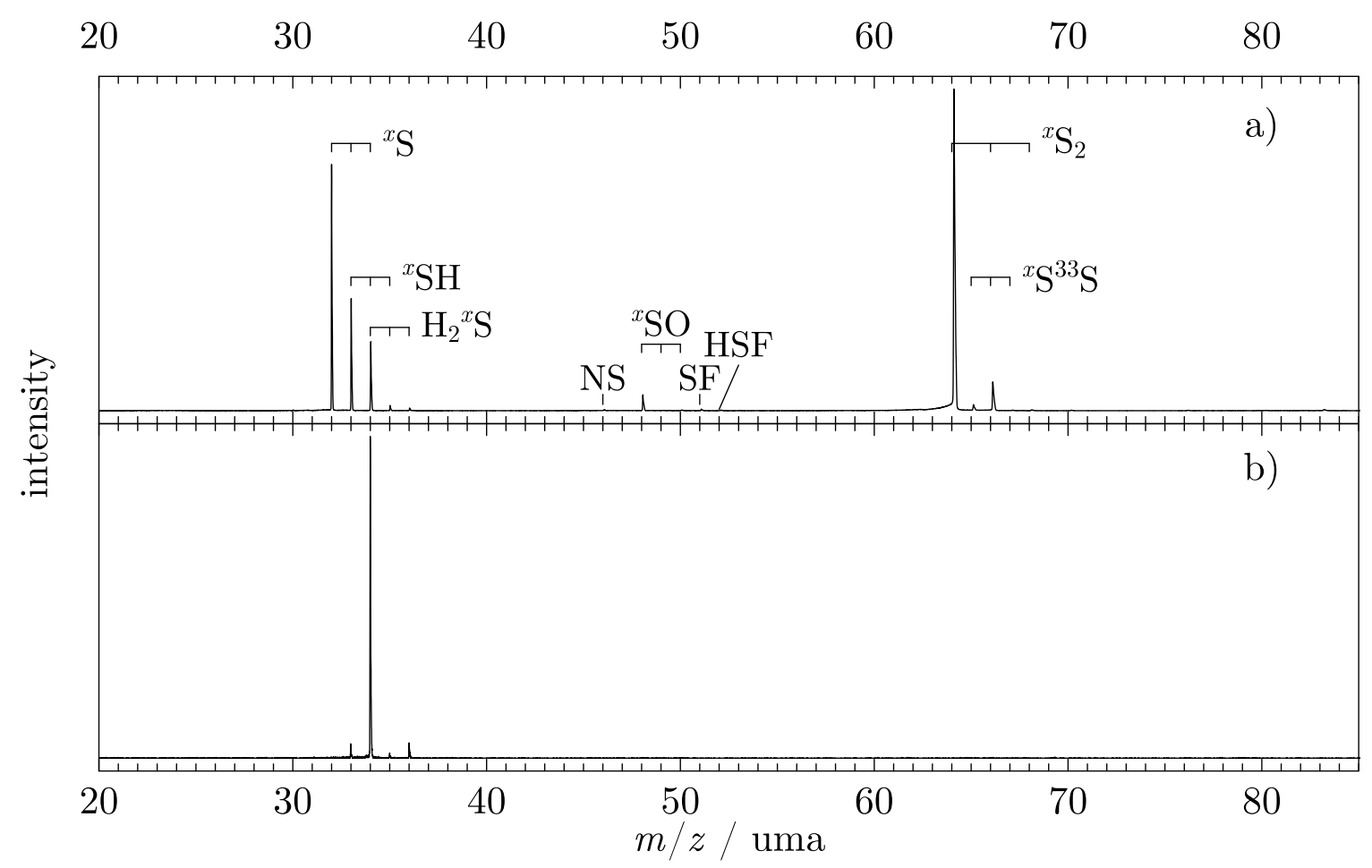

Figure 1. a) TOF mass spectrum integrated between 11.0 and $12.0 \mathrm{eV}$ photon energies for the $\mathrm{H}_{2} \mathrm{~S}+\mathrm{F}$ flow-tube reaction. b) TOF mass spectrum accumulated for two minutes at $11.2 \mathrm{eV}$ photon energy; an example of the measurements made to obtain the absolute photoionization cross section. The clearest distinction between the two mass spectra is the absence of products due to secondary reactions in the flow-tube, most notably $\mathrm{S}_{2}$, due to a lower fluorine concentration to constrain the production of S by double H-abstraction.

\subsection{Total ion yields}

The mass-selected, isotope-corrected, ionization yield of $\mathrm{H}_{2}{ }^{32} \mathrm{~S},{ }^{32} \mathrm{SH}$ and ${ }^{32} \mathrm{~S}$ are presented in Figure 2. From Figure 2 it is evident that all contributions pertaining to atomic sulfur in the 33 amu and 34 amu photoionization yields have been effectively suppressed. Likewise, no ${ }^{33} \mathrm{SH}$ spectroscopic features in the 34 amu photoionization yield are visible. In the top panel of Figure 2 the relative ionization cross section of $\mathrm{H}_{2}{ }^{32} \mathrm{~S}$ compares well to that measured by Watanabe 
and Jursa ${ }^{65}$ (shown in green) apart from one dip in our spectrum which is caused by a slight over-correction from the relatively strong spectroscopic features originating from the ${ }^{34} \mathrm{~S}$ and ${ }^{33} \mathrm{SH}$ photoionization yields in this region, i.e. around $10.7 \mathrm{eV}$. At higher energies there are two absorption features corresponding to Argon absorption lines stemming from the gas filter.

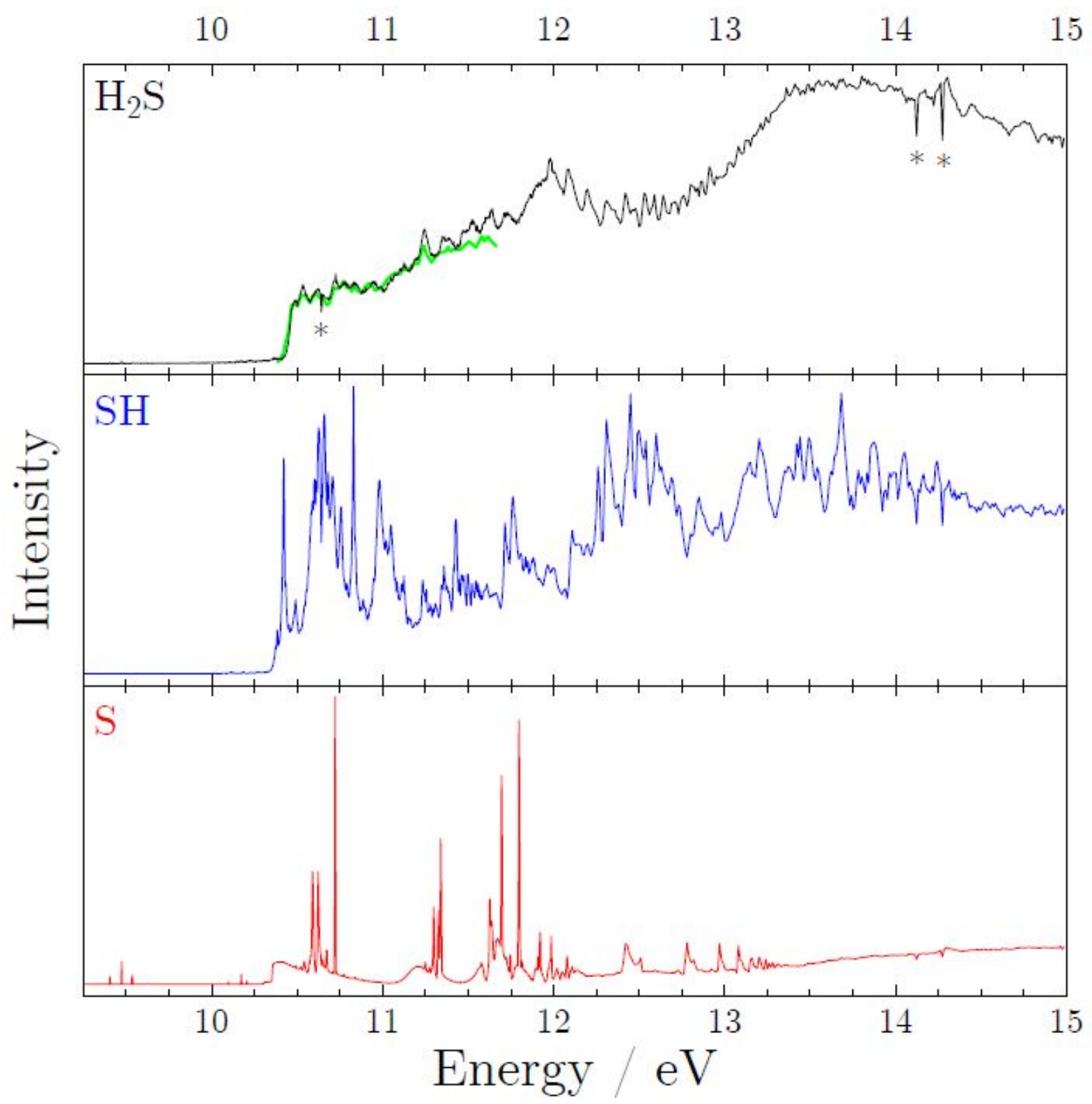

Figure 2 Total photoionization yields of ${ }^{32} \mathrm{~S},{ }^{32} \mathrm{SH}, \mathrm{H}_{2}{ }^{32} \mathrm{~S}$ from 9.7 to $15.0 \mathrm{eV}$. The green inset in the uppermost panel corresponds to the photoionization cross section measured by Watanabe and Jursa. ${ }^{65}$ The star signed features in the $\mathrm{H}_{2} \mathrm{~S}$ photoionization yield correspond to $\mathrm{Ar}$ absorption lines from the gas filter while the feature at $10.68 \mathrm{eV}$ corresponds to an artefact of the isotopic corrections described in section 2.2. 
All three species display a rich variety of structures and spectral fingerprints implying the presence of autoionizing neutral Rydberg states decaying into the ground or excited states of the cations. The exact assignment of all these features is currently outside the scope of this article but it should be noted that assignments of the features in total ionization yield of atomic sulfur have already been performed by Innocenti et al. with constant ion-state spectroscopy (CIS). ${ }^{66}$

In the lowermost panel, weak and sharp features appear below $10.25 \mathrm{eV}$ in the photoionization yield of the $\mathrm{S}$ atoms. These correspond to ionization of metastable $\mathrm{S}$ atoms in the ${ }^{1} \mathrm{D}_{2}$ state $\left(3 \mathrm{~s}^{2} 3 \mathrm{p}^{4}\right)$ which is found to be $1.145 \mathrm{eV}\left(9238.6 \mathrm{~cm}^{-1}\right)$ above the ${ }^{3} \mathrm{P}_{2}$ ground state. ${ }^{58}$ The presence of these metastable $\mathrm{S}$ atoms reflects the exothermicity of the hydrogen abstractions by $\mathrm{F}$ atoms and allowed the determination of the pure photoionization yields relevant to ${ }^{32} \mathrm{SH}$ and $\mathrm{H}_{2}{ }^{32} \mathrm{~S}$, as mentioned in Section 2.2.

\subsection{Absolute photoionization cross section of SH}

The absolute photoionization cross section of the mercapto radical was first determined at the single photon energy of $11.2 \mathrm{eV}$ by using the method that has been applied previously to the $\mathrm{OH}_{,}{ }^{67} \mathrm{CH}_{3},{ }^{68}, \mathrm{C}_{2} \mathrm{H}_{5},{ }^{69}$ and $\mathrm{C}_{4} \mathrm{H}_{5}{ }^{52}$ radicals. The energy for the absolute measurement was carefully chosen so that it was located in a region without autoionization resonances to minimize energy resolution effects, and for which absolute data was available for the reference species, $\mathrm{H}_{2} \mathrm{~S}$ and $\mathrm{S}$. After, a series of mass spectra were recorded at different reaction times (equivalent to different injector distances), with the microwave discharge turned on and off (see Figure S1). With the discharge turned off, $\mathrm{F}$ atom production stops and thus no radicals form in the flow-tube. Under these conditions and with the photon energy set to $11.2 \mathrm{eV}$, only the parent ion, $\mathrm{H}_{2} \mathrm{~S}^{+}$, was produced and the isotopologues $\mathrm{H}_{2}{ }^{32} \mathrm{~S}, \mathrm{H}_{2}{ }^{33} \mathrm{~S}, \mathrm{H}_{2}{ }^{34} \mathrm{~S}$, were observed in the relative ratios $94.84 \%, 0.87 \%$, and $4.30 \%$, respectively. These compare well $(<0.15 \%)$ with the natural abundances. Signals pertaining to the ${ }^{35} \mathrm{~S}$ and ${ }^{36} \mathrm{~S}$ isotopes were not strong enough to be deciphered from the background.

The TOF-integrated signal for the parent ion $\left(\mathrm{H}_{2} \mathrm{~S}^{+}\right)$is proportional to the number of irradiated species in the ionization volume and its photoionization cross section:

$$
S_{\mathrm{H}_{2} \mathrm{~S}}+\propto n_{\mathrm{H}_{2} \mathrm{~S}} * \sigma_{\mathrm{H}_{2} \mathrm{~S}}^{\text {ion }}
$$

Here $S_{\mathrm{H}_{2} \mathrm{~S}}+$ represents the ion signal, $n_{\mathrm{H}_{2} \mathrm{~S}}$ is the number of irradiated parent species, and $\sigma_{\mathrm{H}_{2} \mathrm{~S}}^{i o n}$ is the photoionization cross section of $\mathrm{H}_{2} \mathrm{~S}$. Conservation of matter then assumes that the 
number of free radicals that are produced equals the change in the amount of $\mathrm{H}_{2} \mathrm{~S}$ that is consumed after the discharge is turned on. I.e.:

$$
\Delta n_{\mathrm{H}_{2} \mathrm{~S}}=n_{\mathrm{H}_{2} \mathrm{~S}}^{\mathrm{OFF}}-n_{\mathrm{H}_{2} \mathrm{~S}}^{\mathrm{ON}}=n_{\mathrm{SH}}^{\mathrm{ON}}+n_{\mathrm{S}}^{\mathrm{ON}}
$$

This allows us to write:

$$
\frac{\Delta S_{\mathrm{H}_{2} \mathrm{~S}^{+}}}{\sigma_{\mathrm{H}_{2} \mathrm{~S}}^{\text {ion }}}=\frac{S_{\mathrm{SH}^{+}}}{\sigma_{\mathrm{SH}}^{\text {ion }}}+\frac{S_{\mathrm{S}^{+}}}{\sigma_{\mathrm{S}}^{\text {ion }}}
$$

which enables us to measure the photoionization cross section of the mercapto ( $\mathrm{SH}$ ) radical, using measured values of the photoionization cross sections of $\mathrm{H}_{2} \mathrm{~S}$ and $\mathrm{S}$. Barthel et al. have measured the photoionization cross section of $\mathrm{S}$ atoms ${ }^{70}$ and found $11.4 \pm 2.0 \mathrm{Mb}$ at $11.20 \mathrm{eV}$. Here it should be noted that Barthel et al. recorded the sum of the photoionization cross sections of both the $\mathrm{S}\left({ }^{3} \mathrm{P}\right)$ ground state and the $\mathrm{S}\left({ }^{1} \mathrm{D}\right)$ metastable state. As noted previously, we do see the contribution of $\mathrm{S}\left({ }^{1} \mathrm{D}\right)$ in our measured photoionization cross section, but it is significantly weaker than that of $\mathrm{S}\left({ }^{3} \mathrm{P}\right)$, despite the large cross-section of these autoionizing features (50 $\left.\mathrm{Mb}^{70}\right)$, therefore the contribution from $\mathrm{S}\left({ }^{1} \mathrm{D}\right)$ is negligible. Watanabe and Jursa measured the photoionization cross section of $\mathrm{H}_{2} \mathrm{~S}$ to be $23.6 \pm 4.7 \mathrm{Mb}$ at $11.20 \mathrm{eV}$. ${ }^{65} \mathrm{It}$ is also pertinent to highlight the fact that the low isotopic ${ }^{33} \mathrm{~S}$ abundance (less than $1 \%$ of the ${ }^{32} \mathrm{~S}$ abundance) combined with the low yield of ${ }^{32} \mathrm{~S}$ with the discharge turned on, makes the ${ }^{33} \mathrm{~S}$ signal from the $33 \mathrm{amu}$ ion signal and the ${ }^{34} \mathrm{~S}$ and ${ }^{33} \mathrm{SH}$ signals from the $34 \mathrm{amu}$ ion signal exceedingly small in comparison with the ${ }^{32} \mathrm{SH}$ and $\mathrm{H}_{2}{ }^{32} \mathrm{~S}$ signals, respectively.

Moving the flow-tube injector and altering the reaction time provides a set of 11 independent measurements to estimate the mean and standard deviation of the absolute measurement from a Monte Carlo simulation which also includes the reported errors for the $\mathrm{H}_{2} \mathrm{~S}$ and $\mathrm{S}$ cross-sections. Note that although the reactor conditions were set to minimize secondary reactions, for longer reaction times, $\mathrm{S}$ production is not negligible and needs to be taken into account as written in the above equations. The resulting distribution of values was then fitted with a Gaussian function to derive the mean value and associated error as $14.3 \pm 4.8$ $\mathrm{Mb}(2 \sigma)$ at $11.20 \mathrm{eV}$ (see Figure S2). Note that the majority of the error stems from the uncertainty of the previously measured cross sections of $\mathrm{H}_{2} \mathrm{~S}$ and $\mathrm{S}$, as the normal distribution of our measurements showed a standard deviation smaller than $15 \%$.

The absolute measurement was used to calibrate the photoionization yield of ${ }^{32} \mathrm{SH}$ on an absolute scale and the result is presented in Figure 3, where cross sections are compared with the simulation used by Heays et al. ${ }^{50}$ 
The arbitrarily simulated photoionization cross sections of $\mathrm{SH}$ exhibit non negligible value in the $110-90 \mathrm{~nm}(11.3 \mathrm{eV}-13.8 \mathrm{eV})$ range with a maximum of $5.0 \mathrm{Mb}$ centered approximately $2 \mathrm{eV}$ above the ionization threshold. When compared to our results this wildly underestimates the true photoionization yield that we measure. More precisely, the absolute photoionization cross section curve in the current version of the Leiden database underestimates the photoionization cross section by a factor of at least 10 at its maximum (around $12.4 \mathrm{eV}$ ) and furthermore does not account for any of the strong autoionizing resonances just above the ionization threshold whose maxima range between 50 and $85 \mathrm{Mb}$ at our photon energy resolution. This almost equates to the maximum absolute absorption cross sections of the $\mathrm{SH}$ radical which have been calculated as approaching $90 \mathrm{Mb}$ at approx. $145 \mathrm{~nm}(8.55 \mathrm{eV}) .{ }^{71}$

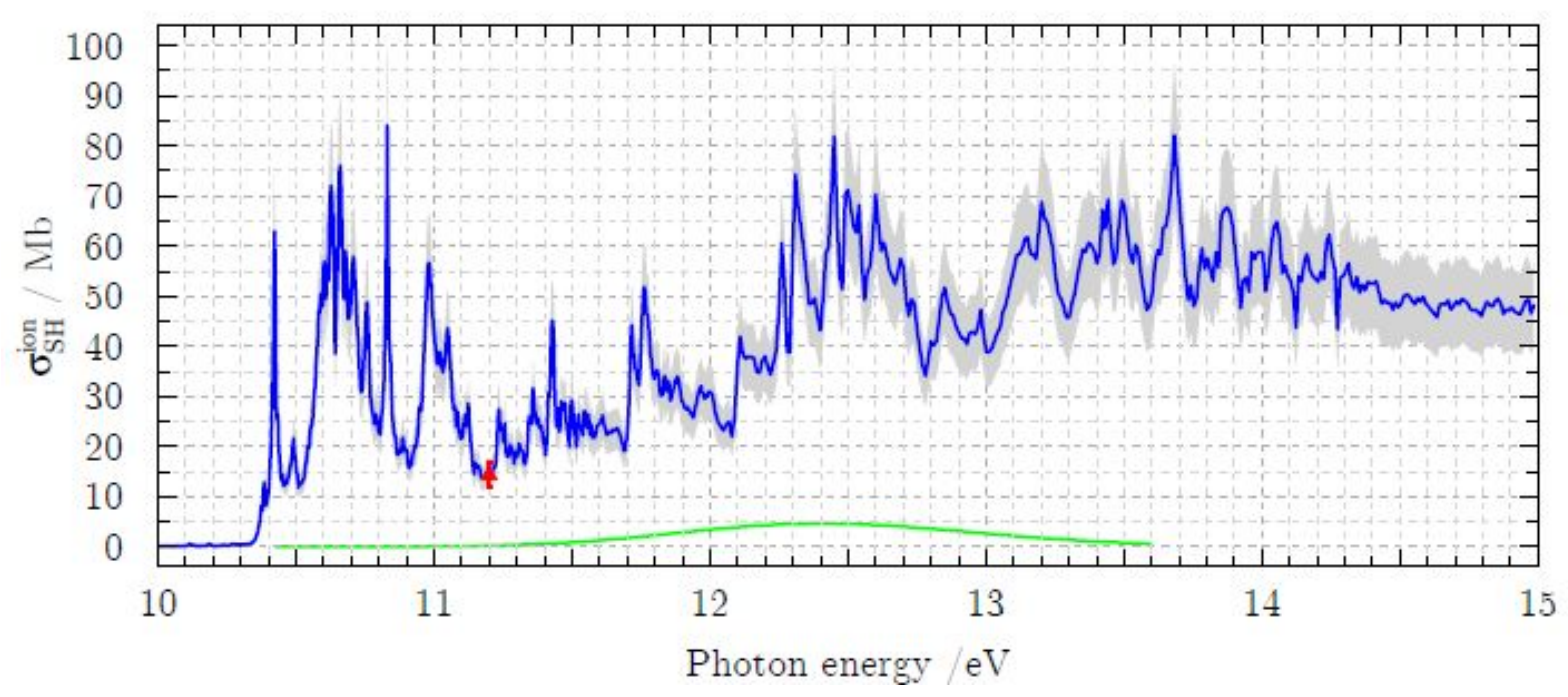

Figure 3. ${ }^{32} \mathrm{SH}^{+}$absolute photoionization cross section (in $\mathrm{Mb}=10^{-18} \mathrm{~cm}^{2}$ ) as a function of the incident photon energy (blue). The red arrow corresponds to the photon energy $(11.2 \mathrm{eV})$ at which the absolute cross section was normalized. The uncertainty of the photoionization yield is presented in gray and is obtained by Monte Carlo uncertainty propagation. In green the arbitrarily simulated $\mathrm{SH}$ photoionization cross section from the Leiden database $\mathrm{e}^{50}$ is presented.

Several structures in the cross section are still observed up until approximately $14 \mathrm{eV}$. Above $14 \mathrm{eV}$ the intensity stays roughly the same within the error bar limits but one would expect a slight decrease because of the predissociation of the $\mathrm{A}^{3} \Pi$ state in $\mathrm{SH}^{+}$(see below).

As presented by Heays et al., current models estimate the photoionization rates of $\mathrm{SH}$ as being below $10^{-10} \mathrm{~s}^{-1}$ while the photodissociation rates of $\mathrm{SH}$ are estimated as being slightly above $10^{-9} \mathrm{~s}^{-1}$. Our measurements, however, suggest that the $\mathrm{SH}$ photoionization rates are much more competitive. Currently, $\mathrm{SH}^{+}$formation in astrochemical models such as the Meudon PDR 
code is predominantly governed by the $\mathrm{H}_{2}+\mathrm{S}^{+}$reaction but with the accompaniment of our measured photoionization cross section for $\mathrm{SH}$, then photoionization might become a viable contributor of astronomical $\mathrm{SH}^{+} .{ }^{72}$

\subsection{Threshold photoelectron spectra (TPES) of $\mathrm{H}_{2} \mathrm{~S}$, SH and $\mathrm{S}$}

The spectroscopy of the cation has been measured with the TPES technique, by scanning the photon energy while considering only electrons with little or no kinetic energy, so that signal is obtained only when the photon energy is resonant with the ionization energy. TPES of $\mathrm{H}_{2} \mathrm{~S}$, $\mathrm{SH}$ and $\mathrm{S}$ with a $12 \mathrm{meV}$ total resolution were recorded according to a method taking full advantage of our electron imaging capabilities as already described elsewhere ${ }^{61}$ (for a review on TPES see Refs. ${ }^{73,74}$ ). The three TPES are depicted in Figure 4.

\subsubsection{Hydrogen sulfide $-\mathrm{H}_{2} \mathrm{~S}^{+}$}

Hydrogen sulfide is a triatomic bent molecule of the $C_{2 v}$ point group. Its ground electronic state has the electron configuration ...(4a $\left(4 a_{1}\right)^{2}\left(2 b_{2}\right)^{2}\left(5 a_{1}\right)^{2}\left(2 b_{1}\right)^{2}$ and its cationic electronic ground state, $\mathrm{H}_{2} \mathrm{~S}^{+}\left(\tilde{\mathrm{X}}^{2} B_{1}\right)$, is formed by removing an electron from the $2 b_{1}$ orbital of $\mathrm{H}_{2} \mathrm{~S}$ which is predominantly non-bonding. Consequently, as noted by Hochlaf et al., ${ }^{75}$ the photoelectron spectrum for $\mathrm{H}_{2} \mathrm{~S}^{+}\left(\tilde{\mathrm{X}}^{2} B_{1}\right)$ is expected to be dominated by the origin vibration band. This is indeed the case in their PFI study as in ours (see upper panel of Figure 4).

Associated with the $\left(\tilde{X}^{2} B_{1}\right)$ ground state are two vibrational progressions, namely the $v_{1}{ }^{+}$symmetric stretching and $v_{2}{ }^{+}$bending modes. Our results are comparable to that of Hochlaf et al. as can be seen from Table S1 in SI where our results for the $\mathrm{H}_{2} \mathrm{~S}^{+}$TPES are compiled and compared. Many of the peaks observed by Hochlaf et al. could not be resolved from other peaks. The TPES peaks were fitted with Lorentzian profiles and the fitted positions are presented in Table S1.

Removal of an electron from the $5 a_{1}$ orbital of $\mathrm{H}_{2} \mathrm{~S}$, gives rise to the $\mathrm{H}_{2} \mathrm{~S}^{+}\left(\tilde{\mathrm{A}}^{2} A_{1}\right)$ state. Hochlaf et al. observed the $v_{2}{ }^{+}$progression of this state between 12.7 and $14.7 \mathrm{eV}$ and they were able to resolve rotational structures in their spectrum. Note, however, that our massselected spectrum drops in intensity around $13.5 \mathrm{eV}$, due to the opening of the dissociative ionization channel that forms $\mathrm{S}^{+}\left({ }^{4} \mathrm{~S}\right)+\mathrm{H}_{2}\left(X^{1} \Sigma_{\mathrm{g}}{ }^{+}\right)$from $13.4 \mathrm{eV}$.

\subsubsection{Sulfanylium ion $\left(\mathrm{SH}^{+}\right)$}


Neutral SH has a $\sigma^{2} \pi^{3}$ open shell electronic configuration. In the ion, the removal of a $\pi$ electron from the open shell gives rise to a ground state with ${ }^{3} \Sigma^{-}$symmetry and two low-lying excited singlet states, $\mathrm{a}^{1} \Delta$, and $\mathrm{b}^{1} \Sigma^{+}$. The removal of a $\sigma$ electron leads to the cationic $\mathrm{A}^{3} \Pi$ state. In our recorded TPES of $\mathrm{SH}^{+}$(see middle panel of Figure 4), there are a few spectral features observed whose origins are traced to these states. The photoionizing transitions towards the two lowest excited vibrational levels of the $\mathrm{X}^{3} \Sigma^{-}$ground state are observed at $10.422 \mathrm{eV}$ and 10.719 $\mathrm{eV}$. The origin bands of the $\mathrm{a}^{1} \Delta, \mathrm{b}^{1} \Sigma^{+}$, and $\mathrm{A}^{3} \Pi$ states are observed at $11.643 \mathrm{eV}, 12.728 \mathrm{eV}$, and $14.098 \mathrm{eV}$, respectively. These values are compiled and compared with the results of Dunlavey et al. ${ }^{17}$ in Table 2 and there are some discrepancies to be found, most notably the ground state $\mathrm{X}^{3} \Sigma^{-}$and the $\mathrm{b}^{1} \Sigma^{+}$state.

In the experiments of Dunlavey et al., the spectrum was not mass resolved, meaning that signals pertaining to photoionization of both $\mathrm{H}_{2} \mathrm{~S}$ and $\mathrm{S}$ could have clouded their spectra. Furthermore, the value they cite for the ground state is the value we measure for the ionization of the $\Omega=1 / 2$ spin-orbit component of the SH ground state. It should be mentioned that contributions from a sequence band, i.e. $v^{\prime \prime}=1 \leftarrow v^{+}=1$, would be found at very similar energies as the origin band of the same spin-orbit component. However, while the $\mathrm{X}^{2} \Pi_{1 / 2}$ state is $47 \mathrm{meV}$ above the $\mathrm{X}^{2} \Pi_{3 / 2}$ state, the first vibrational band of the $\mathrm{X}^{2} \Pi_{3 / 2}$ state is $350 \mathrm{meV}$ higher in energy. The $\mathrm{X}^{2} \Pi_{1 / 2}$ state is more easily populated, and this is verified by simulations (see Figure S3). Due to spectral congestion, lack of mass selectivity and the added spin-orbit component of the SH ground state, it is quite likely that Dunlavey et al. incorrectly assigned the origin band.

This brings about an interesting point regarding the flow-tube which is its propensity to produce species that are vibrationally hot whilst being rotationally cooled. Vibrationally hot species have already been produced in a similar manner via $\mathrm{H}$-abstractions by fluorine radicals, e.g. $\mathrm{CH},{ }^{76}(\mathrm{REF})$ but the pressures within the flow-tube are high enough so that rotational excitation is quenched by collisions (e.g. $\mathrm{NH},{ }^{77} \mathrm{CH}_{2},{ }^{78} \mathrm{CH}_{\mathrm{X}} \mathrm{CN}^{79}$ ). Electronic excitation with different multiplicities than the ground state are also populated, such as the metastable S(1D) atoms here. For states of the same multiplicity, the relaxation is prompt and as such the corresponding rotational temperatures would be equally small whilst the vibrational temperature is relatively high.

As for the $b^{1} \Sigma^{+}$state, it was found to exhibit broader peaks as compared with the rest of the bands in their PES study. The accuracy in the determination of the ionization onset of the state can be called into question due to the aforementioned spectral congestion. As stated 
previously, our values are calibrated with the appearance of S atomic lines from the NIST database. ${ }^{58}$ As such, we present our results with a confidence interval that is $2 \mathrm{meV}$ below 12 $\mathrm{eV}$ and $6 \mathrm{meV}$ between $12 \mathrm{eV}$ and $15 \mathrm{eV}$.

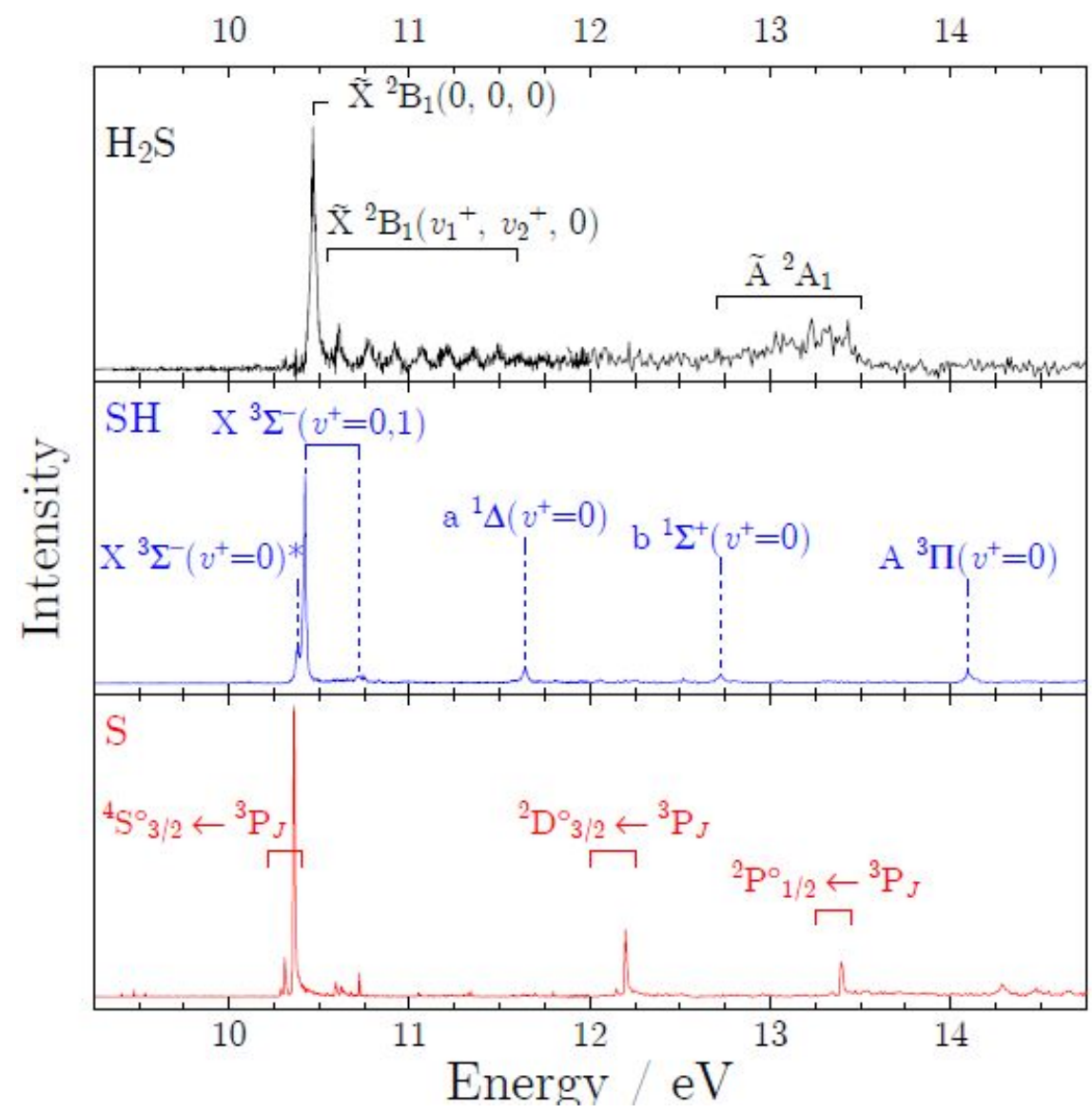

Figure 4. Experimental TPES of $\mathrm{H}_{2} \mathrm{~S}$ (top - black), $\mathrm{SH}$ (middle - blue), and $\mathrm{S}$ (bottom - red). The total energy resolution is $12 \mathrm{meV}$ The assignment marked with an asterisk in the $\mathrm{SH}$ spectrum corresponds to the photoionization of the $\Omega=1 / 2$ spin-orbit component of the $\mathrm{SH}$ ground state.

Table 2. Energies of the TPES peaks for the electronic states of $\mathrm{SH}^{+}$observed in the middle panel of Figure 4.

\begin{tabular}{|l|l|l|}
\hline Electronic state & Energy $(\mathrm{eV})-$ our values & Energy $(\mathrm{eV})-$ Dunlavey et al. ${ }^{17,80}$ \\
\hline$X^{3} \Sigma^{-}\left(v^{+}=0\right)^{*}$ & 10.375 & \\
\hline$X^{3} \Sigma^{-}\left(v^{+}=0\right)$ & 10.422 & 10.37 \\
\hline$X^{3} \Sigma^{-}\left(v^{+}=1\right)$ & 10.719 & - \\
\hline
\end{tabular}




\begin{tabular}{|l|l|l|}
\hline$a^{1} \Delta\left(v^{+}=0\right)$ & 11.643 & 11.65 \\
\hline$b^{1} \Sigma^{+}\left(v^{+}=0\right)$ & 12.728 & 12.76 \\
\hline $\mathrm{A}^{3} \Pi\left(v^{+}=0\right)$ & 14.098 & 14.11 \\
\hline $\mathrm{A}^{3} \Pi\left(v^{+}=1\right)$ & 14.296 & $14.30^{* *}$ \\
\hline $\mathrm{A}^{3} \Pi\left(v^{+}=2\right)$ & 14.477 & $14.49^{* *}$ \\
\hline $\mathrm{A}^{3} \Pi\left(v^{+}=3\right)$ & 14.652 & $14.66^{* *}$ \\
\hline
\end{tabular}

*Excitation from the $\Omega=1 / 2$ spin-orbit component of the $\mathrm{SH}$ ground state $\&$ contribution from the $v^{+}=1 \leftarrow v^{\prime \prime}=1$ hot band.

**Estimated values from the $\omega_{\mathrm{e}}$ and $\omega_{\mathrm{e}} x_{\mathrm{e}}$ values presented by Dunlavey et al.

Dunlavey et al. ${ }^{17}$ observed and assigned more vibrational bands of the $\mathrm{A}^{3} \Pi$ state and we do indeed observe these bands as well. However, they are observed in the $\mathrm{S}^{+}$channel of the TPES (Figure 5) as the $\mathrm{A}^{3} \Pi$ state interacts with a repulsive state $\left({ }^{5} \Sigma^{-}\right)$and thus predissociates to $\mathrm{S}^{+}\left({ }^{4} \mathrm{~S}^{0}\right)+\mathrm{H}\left({ }^{2} \mathrm{~S}\right)$ for $\mathrm{v}^{+} \geq 1$, as seen in the potential energy curves shown in Figure 6 . This observation is in line with prior studies, both experimental ${ }^{18,19,40}$ and theoretical. ${ }^{19,43,46}$ This confirms that the $\mathrm{v}^{+}>0$ vibrational levels are purely dissociative within the timeframe that ions spend inside the acceleration region of DELICIOUS3, i.e., a few $\mu$ sec.

According to the calculations of Brites et al. ${ }^{46}$ the predissociative lifetime of the $\mathrm{A}^{3} \Pi$ decreases significantly above $v^{+}=0$. Namely, the $\mathrm{A}^{3} \Pi\left(v^{+}=1,2,3\right)$ states were calculated to exhibit a predissociative lifetime of $10.26 \mathrm{~ns}, 44.89 \mathrm{ps}$ and $1.54 \mathrm{ps}$, respectively. In DELICIOUS3, under the current experimental conditions, ions traverse the acceleration region in a matter of a few $\mu$ s. Thus, we would not expect to observe any parent species with such short predissociative lifetimes. Conversely, the $\mathrm{A}^{3} \Pi\left(v^{+}=0\right)$ state was reported to have a predissociative lifetime of $38.68 \mu \mathrm{s}$, meaning that it would predissociate only after exiting the acceleration region of DELICIOUS3 and therefore we do not detect it in the $\mathrm{S}^{+}$channel. 


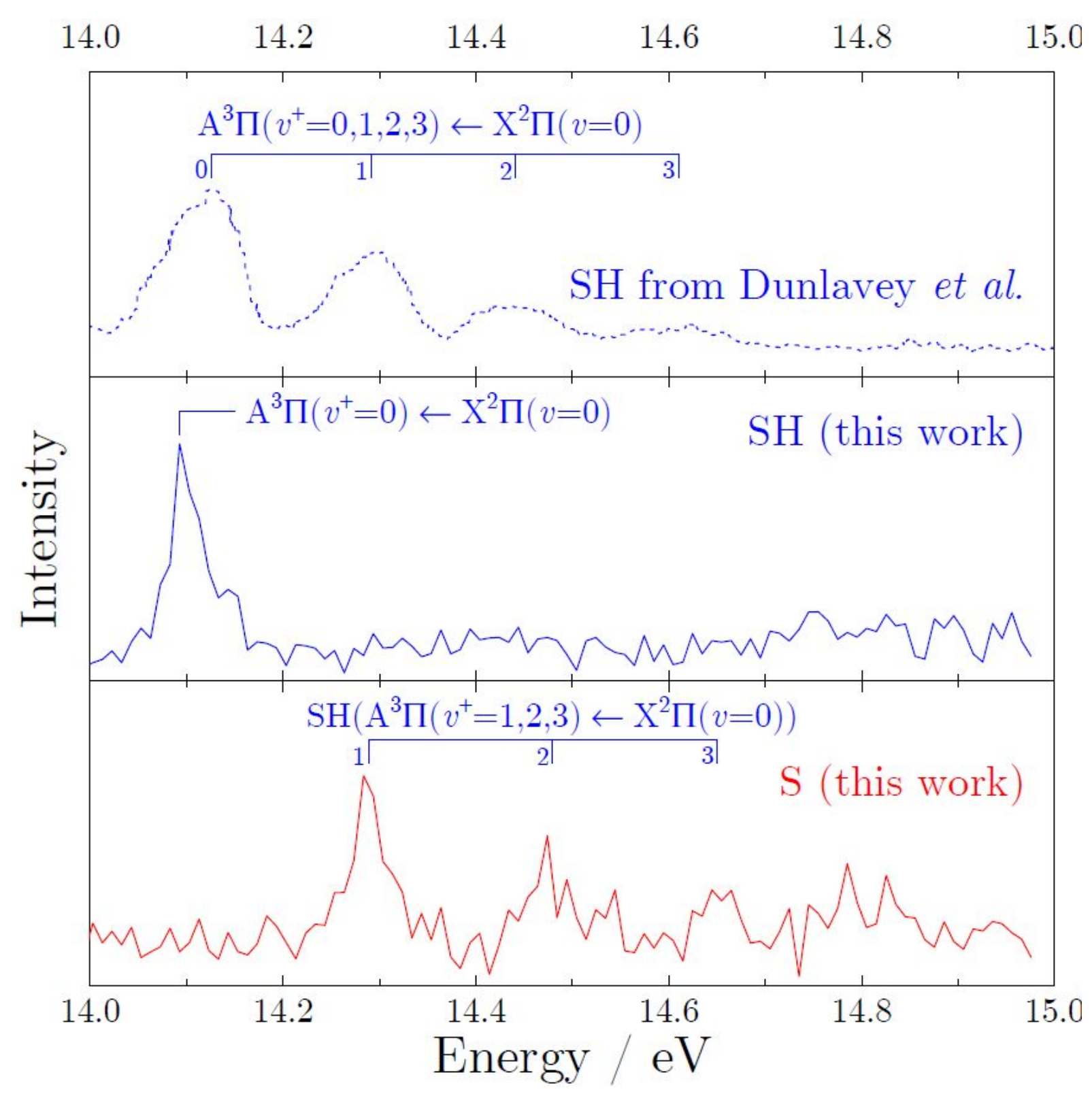

Figure 5. Comparison of the $A^{3} \Pi$ state as observed in the PES from Dunlavey et al. ${ }^{17}$ (top panel) and in our TPES of SH (middle panel) and S (bottom panel). 


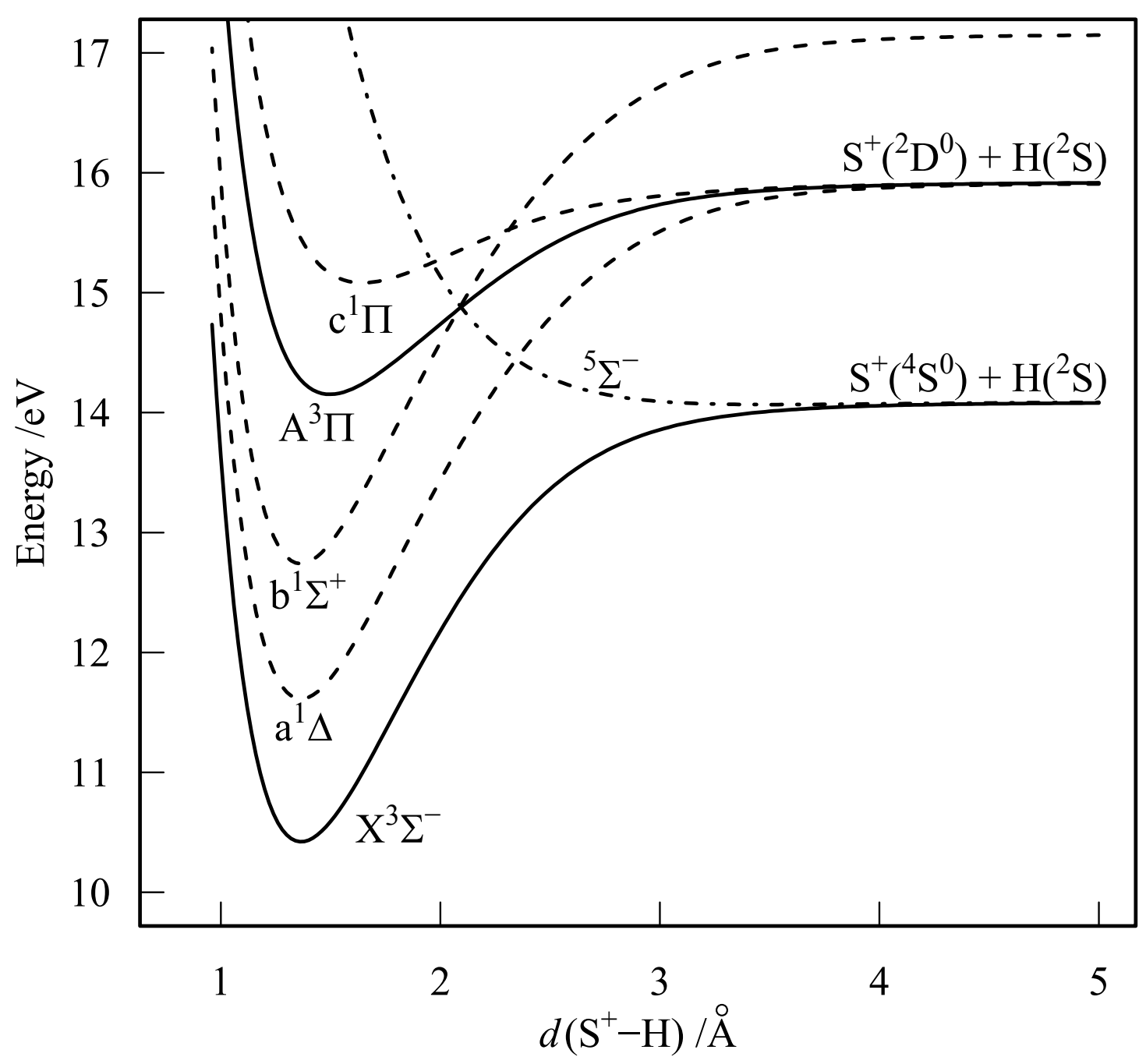

Figure 6. Potential energy curves that are relevant to the $\mathrm{SH}^{+}$cation versus the ground state of neutral $\mathrm{SH})$. Presented are two dissociative thresholds for the formation of $\mathrm{S}^{+}$, namely $\mathrm{S}^{+}\left({ }^{4} \mathrm{~S}^{0}\right)$ and $\mathrm{S}^{+}\left({ }^{2} \mathrm{D}^{0}\right)$, but in the current study we did not proceed to high enough energies to study $\mathrm{S}^{+}$ formation above the $\mathrm{S}^{+}\left({ }^{2} \mathrm{D}^{0}\right)+\mathrm{H}\left({ }^{2} \mathrm{~S}\right)$ threshold.

\subsection{3 $S^{+}$atoms}

An exhaustive study of the photoionization of neutral S atoms in the ground state and metastable states has already been carried out by Barthel et al. ${ }^{70}$ by using tunable VUV radiation in the energy range $9-30 \mathrm{eV}$. Hence, only the most prominent features in our TPES will be briefly discussed here below. 
Our TPES of the S atoms reveal several weak autoionizations from Rydberg series as well as direct ionizations, where the excited/ejected electron is originated from the ground state of sulfur $\left(3 s^{2} 3 p^{4}{ }^{3} \mathrm{P}_{2,1,0}\right)$ as well as from the metastable $3 s^{2} 3 p^{4}{ }^{1} \mathrm{D}_{2}$ state. The ${ }^{3} \mathrm{P}_{1},{ }^{3} \mathrm{P}_{0}$ and ${ }^{1} \mathrm{D}_{2}$ states all lie $396.055 \mathrm{~cm}^{-1}(0.0491 \mathrm{eV}), 573.640 \mathrm{~cm}^{-1}(0.0711 \mathrm{eV})$, and $9238.609 \mathrm{~cm}^{-1}(1.1454$ $\mathrm{eV})$, respectively, above the ${ }^{3} \mathrm{P}_{2}$ state. Valence shell photoionization of neutral $\mathrm{S}\left({ }^{3} P_{2}\right)$ atoms produces the ionic continuum states $\mathrm{S}^{+}\left({ }^{4} \mathrm{~S}^{\circ}\right), \mathrm{S}^{+}\left({ }^{2} \mathrm{D}^{\circ}\right)$, and $\mathrm{S}^{+}\left({ }^{2} \mathrm{P}^{\circ}\right)$ which have ionization potentials of 10.36, 12.20, and $13.40 \mathrm{eV}$, respectively. ${ }^{58}$ Our results are compiled in Table S2.

Direct ionizations from the ${ }^{3} \mathrm{P}_{2,1,0}$ ground state/s to the $\mathrm{S}^{+} 3 s^{2} 3 p^{3}\left[{ }^{4} \mathrm{~S}_{3 / 2}^{\circ}\right]$ ground state are observed at $10.360 \mathrm{eV}, 10.309 \mathrm{eV}$, and $10.288 \mathrm{eV}$, respectively. Similarly, direct ionizations to the $\mathrm{S}^{+} 3 s^{2} 3 p^{3}\left[{ }^{2} \mathrm{D}_{3 / 2}^{\circ}\right]$ state from the ${ }^{3} \mathrm{P}_{2,1}$ ground state are observed at $12.199 \mathrm{eV}$ and $12.149 \mathrm{eV}$. A very weak signal at $11.051 \mathrm{eV}$ is attributed to direct ionization of metastable $\mathrm{S}\left({ }^{1} \mathrm{D}_{2}\right)$ atoms to the $\mathrm{S}^{+}\left({ }^{2} \mathrm{D}_{3 / 2}^{\circ}\right)$ ionic state.

Three weak peaks are observed around $9.5 \mathrm{eV}$, approximately $0.87 \mathrm{eV}$ below the direct ionization threshold of the ${ }^{3} \mathrm{P}_{2}$ ground state. These signals correspond to excitations from $\mathrm{S}\left({ }^{1} \mathrm{D}_{2}\right)$ to a Rydberg series above the ionization threshold which promptly autoionize. These transitions have been well characterized but the peak we observe at $9.413 \mathrm{eV}$ was observed but only tentatively assigned as a $3 s^{2} 3 p^{3}\left[{ }^{2} \mathrm{D}^{\circ}\right] 3 d$ state but without a corresponding term symbol. ${ }^{70}$ Unassigned lines correspond to autoionization due to imperfect hot electron subtraction.

\section{SUMMARY AND CONCLUSIONS}

Here we present the first measurement of the absolute photoionization cross section of the ${ }^{32} \mathrm{SH}$ radical over a large photon energy range, calibrated at the photon energy of $11.2 \mathrm{eV}$ using the known values for $\mathrm{H}_{2} \mathrm{~S}^{65}$ and $\mathrm{S}^{70}$. The uncertainty we present with the measured cross section mainly stems from these reference values, but within our error bars the cross section we measured is significantly different from the arbitrarily estimated photoionization cross section that is currently used in the Leiden cross section database..$^{50}$

The mass-selectivity of our i $^{2}$ PEPICO spectra allowed us to experimentally verify the predissociative inclination of the $\mathrm{A}^{3} \Pi\left(v^{+}>0\right)$ states, as a vibrational progression was observed in the $\mathrm{S}^{+}$portion of the TPES and only the $\mathrm{A}^{3} \Pi\left(v^{+}=0\right)$ state was observed in the TPES of SH. To estimate any effects these results would have on the overall sulfur chemistry of the interstellar medium, further calculations would be required that are outside the scope of this work. 


\section{ACKNOWLEDGMENTS}

We warmly thank the whole SOLEIL staff for running smoothly the facility under project 99180002. We are indebted to JF Gil for its help on the SAPHIRS chamber. The research described in this work has received financial support from the French Agence Nationale de la Recherche (ANR) under Grant No. ANR-12-BS08-0020-02 (project SYNCHROKIN).

\section{REFERENCES}

1. S. R. Federman, Y. Sheffer, D. L. Lambert and R. L. Gilliland, Astrophys. J., 1993, 413, L51-L54.

2. B. A. McGuire, Astrophys. J. Suppl. Ser., 2018, 239, 48.

3. K. M. Menten, F. Wyrowski, A. Belloche, R. Gusten, L. Dedes and H. S. P. Muller, Astron. Astrophys., 2011, 525, 15.

4. D. A. Neufeld, E. Falgarone, M. Gerin, B. Godard, E. Herbst, G. P. des Forets, A. I. Vasyunin, R. Gusten, H. Wiesemeyer and O. Ricken, Astron. Astrophys., 2012, 542, 4.

5. D. A. Neufeld, B. Godard, M. Gerin, G. P. des Forets, C. Bernier, E. Falgarone, U. U. Graf, R. Guesten, E. Herbst, P. Lesaffre, P. Schilke, P. Sonnentrucker and H. Wiesemeyer, Astron. Astrophys., 2015, 577, 29.

6. B. Godard, E. Falgarone, M. Gerin, D. C. Lis, M. De Luca, J. H. Black, J. R. Goicoechea, J. Cernicharo, D. A. Neufeld, K. M. Menten and M. Emprechtinger, Astron. Astrophys., 2012, 540, 21.

7. D. Zhao, G. A. Galazutdinov, H. Linnartz and J. Krelowski, Astron. Astrophys., 2015, $\mathbf{5 7 9}, 4$.

8. T. J. Millar, N. G. Adams, D. Smith, W. Lindinger and H. Villinger, Mon. Not. Roy. Astron. Soc., 1986, 221, 673-678.

9. B. Godard, E. Falgarone and G. P. des Forets, Astron. Astrophys., 2014, 570, 22.

10. W. e. al., 2012.

11. T. Lamberts and J. Kastner, J. Phys. Chem. A, 2017, 121, 9736-9741.

12. A. Zanchet, M. Agundez, V. Herrero, A. Aguado and O. Roncero, Astronomical Journal, 2013, 146, 125.

13. T. H. G. Vidal, J. C. Loison, A. Y. Jaziri, M. Ruaud, P. Gratier and V. Wakelam, Mon. Not. Roy. Astron. Soc., 2017, 469, 435-447.

14. D. Semenov, C. Favre, D. Fedele, S. Guilloteau, R. Teague, T. Henning, A. Dutrey, E. Chapillon, F. Hersant and V. Pietu, Astron. Astrophys., 2018, 617, 15.

15. T. H. G. Vidal and V. Wakelam, Mon. Not. Roy. Astron. Soc., 2018, 474, 5575-5587.

16. C. Vastel, D. Quenard, R. Le Gal, V. Wakelam, A. Andrianasolo, P. Caselli, T. Vidal, C. Ceccarelli, B. Lefloch and R. Bachiller, Mon. Not. Roy. Astron. Soc., 2018, 478, 5519-5537.

17. S. J. Dunlavey, J. M. Dyke, N. K. Fayad, N. Jonathan and A. Morris, Mol. Phys., 1979, 38, 729-738. 
18. C. P. Edwards, C. S. Maclean and P. J. Sarre, Mol. Phys., 1984, 52, 1453-1466.

19. J. Rostas, M. Horani, J. Brion, D. Daumont and J. Malicet, Mol. Phys., 1984, 52, 14311452.

20. P. R. Brown, P. B. Davies and S. A. Johnson, Chemical Physics Letters, 1986, 132, 582584.

21. D. C. Hovde and R. J. Saykally, J. Chem. Phys., 1987, 87, 4332-4338.

22. D. Zeitz, T. Nelis and W. Urban, Mol. Phys., 1987, 60, 255-261.

23. W. Ubachs, L. Tashiro and R. N. Zare, Chem. Phys., 1989, 130, 1-13.

24. S. Civis, C. Blom and P. Jense, Journal of Molecular Spectroscopy, 1989, 138, 69-78.

25. A. Levick and P. Sarre, Journal of Molecular Spectroscopy, 1989, 133, 227-229.

26. M. N. R. Ashfold, B. Tutcher and C. Western, Mol. Phys., 1989, 66, 981-991.

27. C. W. Hsu, D. P. Baldwin, C. L. Liao and C. Y. Ng, J. Chem. Phys., 1994, 100, 80478054.

28. S. H. S. Wilson, J. D. Howe and M. N. R. Ashfold, Mol. Phys., 1996, 88, 841-858.

29. J. Milan, W. Buma and C. de Lange, J. Chem. Phys., 1996, 105, 6688-6712.

30. J. Milan, W. Buma and C. De Lange, J. Chem. Phys., 1996, 104, 521-527.

31. P. A. Cook, S. R. Langford, R. N. Dixon and M. N. R. Ashfold, J. Chem. Phys., 2001, 114, 1672-1684.

32. C. Savage, A. Apponi and L. Ziurys, Astrophys. J., 2004, 608, L73-L76.

33. L. Zuin, F. Innocenti, M. L. Costa, A. A. Dias, A. Morris, A. C. S. Paiva, S. Stranges, J. B. West and J. M. Dyke, Chem. Phys., 2004, 298, 213-222.

34. K. Le Guen, C. Miron, D. Ceolin, R. Guillemin, N. Leclercq, M. Simon, P. Morin, A. Mocellin, O. Bjorneholm, A. N. de Brito and S. L. Sorensen, J. Chem. Phys., 2007, 127, 6.

35. L. M. C. Janssen, M. P. J. van der Loo, G. C. Groenenboom, S. M. Wu, D. C. Radenovic, A. J. A. van Roij, I. A. Garcia and D. H. Parker, J. Chem. Phys., 2007, 126, 8.

36. R. A. Rose, A. J. Orr-Ewing, C. H. Yang, K. Vidma, G. C. Groenenboom and D. H. Parker, J. Chem. Phys., 2009, 130, 14.

37. J. Brown and H. S. P. Muller, Journal of Molecular Spectroscopy, 2009, 255, 68-71.

38. D. T. Halfen and L. M. Ziurys, Astrophys. J., 2015, 814, 4.

39. J. Senekowitsch, H. J. Werner, P. Rosmus, E. A. Reinsch and S. V. Oneil, J. Chem. Phys., 1985, 83, 4661-4667.

40. O. Gustafsson, M. Larsson and P. Sigray, Zeitschrift fur Physik D-Atoms Molecules and Clusters, 1988, 7, 373-378.

41. B. Minaev, A. Buketova and Z. Muldahmetov, Spectroscopy Letters, 1989, 22, 211 236.

42. R. Gonzalez-Luque, M. Merchan and B. Roos, Mol. Phys., 1992, 76, 201-210.

43. J. Park and H. Sun, Chemical Physics Letters, 1992, 194, 485-491.

44. P. Stancil, K. Kirby, J. Gu, G. Hirsch, R. Buenker and A. Sannigrahi, Astronomy \& Astrophysics Supplement Series, 2000, 142, 107-112.

45. F. Khadri, H. Ndome, S. Lahmar, Z. Ben Lakhdar and M. Hochlaf, Journal of Molecular Spectroscopy, 2006, 237, 232-240.

46. V. Brites, D. Hammoutene and M. Hochlaf, Journal of Physics B-Atomic Molecular and Optical Physics, 2008, 41, 045101.

47. D. H. Shi, J. P. Mang, Y. F. Liu, J. F. Sun and Z. L. Zhu, Int. J. Quantum Chem., 2009, 109, 1159-1166.

48. X. Y. Liu, C. L. Yang, M. S. Wang, X. G. Ma and W. W. Liu, Comput. Theor. Chem., 2012, 979, 44-48.

49. E. C. McMillan, G. Shen, J. F. McCann, B. M. McLaughlin and P. C. Stancil, Journal of Physics B-Atomic Molecular and Optical Physics, 2016, 49, 8. 
50. A. N. Heays, A. D. Bosman and E. F. van Dishoeck, Astron. Astrophys., 2017, 602, 62.

51. O. J. Harper, M. Hassenfratz, J. C. Loison, G. A. Garcia, N. de Oliveira, H. R. Hrodmarsson, S. T. Pratt, S. Boye-Peronne and B. Gans, J. Chem. Phys., 2019, 150, 6.

52. H. R. Hrodmarsson, J. C. Loison, U. Jacovella, D. M. P. Holland, S. Boye-Peronne, B. Gans, G. A. Garcia, L. Nahon and S. T. Pratt, J. Phys. Chem. A, 2019, 123, 1521-1528.

53. G. A. Garcia, X. Tang, J. F. Gil, L. Nahon, M. Ward, S. Batut, C. Fittschen, C. A. Taatjes, D. L. Osborn and J. C. Loison, J Chem Phys, 2015, 142, 164201.

54. G. Schonle, M. M. Rahman and R. N. Schindler, Ber. Bunsen-Ges. Phys. Chem. Chem. Phys., 1987, 91, 66-75.

55. A. Persky, Chemical Physics Letters, 1998, 298, 390-394.

56. L. Nahon, N. de Oliveira, G. A. Garcia, J. F. Gil, B. Pilette, O. Marcouille, B. Lagarde and F. Polack, J. Synchrot. Radiat., 2012, 19, 508-520.

57. X. F. Tang, G. A. Garcia, J. F. Gil and L. Nahon, Rev. Sci. Instrum., 2015, 86, 8.

58. A. Kramida, Y. Ralchenko, J. Reader and N. A. Team, National Institute of Standards and Technology, Gaithersburg, MD2018.

59. G. A. Garcia, B. K. C. de Miranda, M. Tia, S. Daly and L. Nahon, Rev. Sci. Instrum., 2013, 84, 11.

60. G. A. Garcia, L. Nahon and I. Powis, Rev. Sci. Instrum., 2004, 75, 4989-4996.

61. G. Garcia, H. Soldi-Lose and L. Nahon, Review of Scientific Instruments, 2009, 80, 023102.

62. B. Sztaray and T. Baer, Rev. Sci. Instrum., 2003, 74, 3763-3768.

63. H. F. Prest, W. B. Tzeng, J. M. Brom and C. Y. Ng, Int. J. Mass Spectrom. Ion Process., 1983, 50, 315-329.

64. H.-J. Werner, P. J. Knowles, G. Knizia, F. R. Manby and M. Schutz, Wiley Interdisciplinary Reviews: Computational Molecular Science, 2012, 2, 242-253.

65. K. Watanabe and A. S. Jursa, J. Chem. Phys., 1964, 41, 1650-\&.

66. F. Innocenti, L. Zuin, M. L. Costa, A. A. Dias, A. Morris, S. Stranges and J. M. Dyke, J. Chem. Phys., 2007, 126, 13.

67. O. J. Harper, M. Hassenfratz, J.-C. Loison, G. A. Garcia, N. de Oliveira, H. R. Hrodmarsson, S. T. Pratt, S. Boyé-Péronne and B. Gans, Journal of Chemical Physics Communications, 2019, [accepted].

68. J. C. Loison, J. Phys. Chem. A, 2010, 114, 6515-6520.

69. B. Gans, G. A. Garcia, S. Boye-Peronne, J. C. Loison, S. Douin, F. Gaie-Levrel and D. Gauyacq, J. Phys. Chem. A, 2011, 115, 5387-5396.

70. M. Barthel, R. Flesch, E. Ruhl and B. M. McLaughlin, Phys. Rev. A, 2015, 91, 17.

71. P. J. Bruna and G. Hirsch, Mol. Phys., 1987, 61, 1359-1380.

72. A. Heays, personal communication.

73. T. Baer and R. P. Tuckett, Phys Chem Chem Phys, 2017, 19, 9698-9723.

74. J. M. Dyke, Phys. Chem. Chem. Phys., 2019, 21, 9106-9136.

75. M. Hochlaf, K. M. Weitzel and C. Y. Ng, J. Chem. Phys., 2004, 120, 6944-6956.

76. B. Gans, F. Holzmeier, J. Kruger, C. Falvo, A. Röder, A. Lopes, G. A. Garcia, C. Fittschen, J. C. Loison and C. Alcaraz, J. Chem. Phys., 2016, 144, 204307.

77. G. A. Garcia, B. Gans, X. Tang, M. Ward, S. Batut, L. Nahon, C. Fittschen and J. C. Loison, Journal of Electron Spectroscopy and Related Phenomena, 2015, 203, 25-30.

78. L. H. Coudert, B. Gans, F. Holzmeier, J. C. Loison, G. A. Garcia, C. Alcaraz, A. Lopes and A. Röder, J. Chem. Phys., 2018, 149, 224304.

79. G. A. Garcia, J. Kruger, B. Gans, C. Falvo, L. H. Coudert and J. C. Loison, J. Chem. Phys., 2017, 147, 8.

80. S. J. Dunlavey, J. M. Dyke, N. K. Fayad, N. Jonathan and A. Morris, Mol. Phys., 1981, 44, 265-266. 


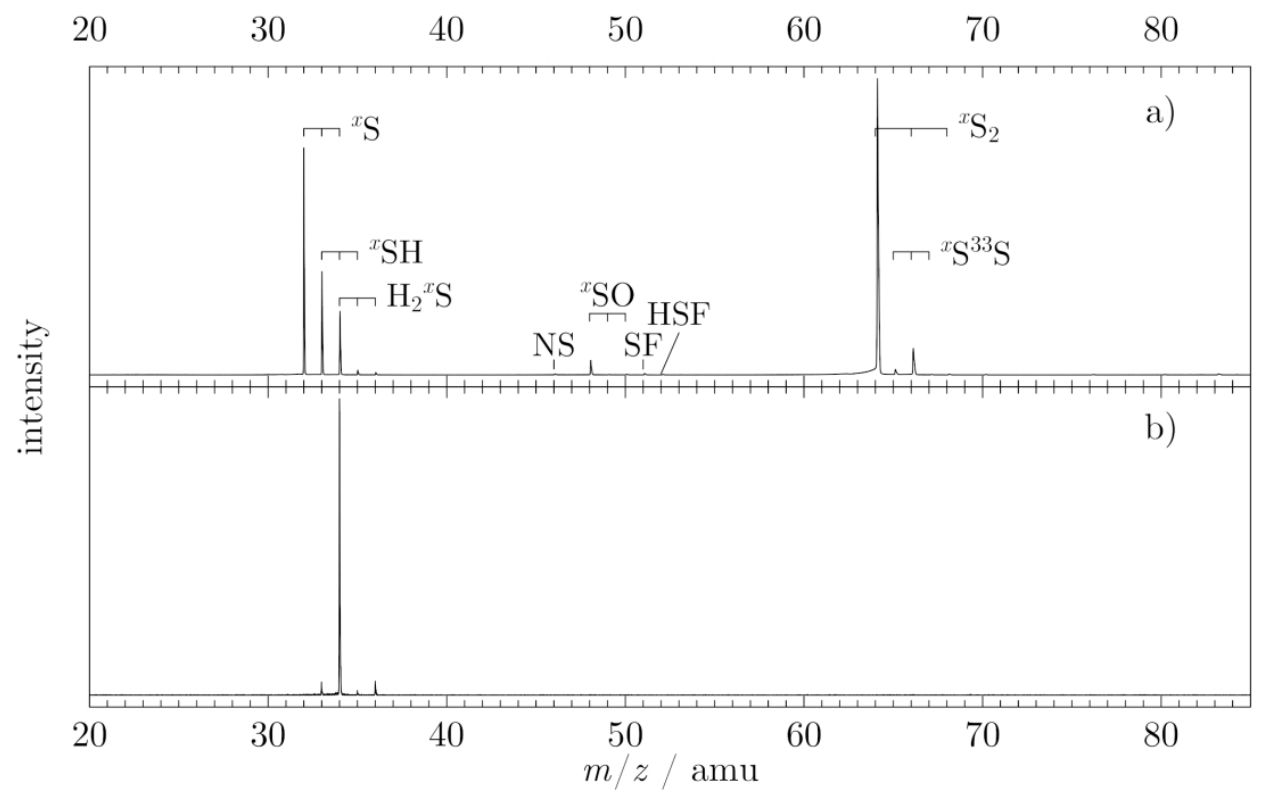

a) TOF mass spectrum integrated between 11.0 and $12.0 \mathrm{eV}$ photon energies for the $\mathrm{H}_{2} \mathrm{~S}+\mathrm{F}$ flow-tube reaction. b) TOF mass spectrum accumulated for two minutes at $11.2 \mathrm{eV}$ photon energy; an example of the measurements made to obtain the absolute photoionization cross section. The clearest distinction between the two mass spectra is the absence of products due to secondary reactions in the flow-tube, most notably

$\mathrm{S}_{2}$, due to a lower fluorine concentration to constrain the production of $\mathrm{S}$ by double $\mathrm{H}$-abstraction.

$845 \times 528 \mathrm{~mm}(72 \times 72$ DPI $)$ 


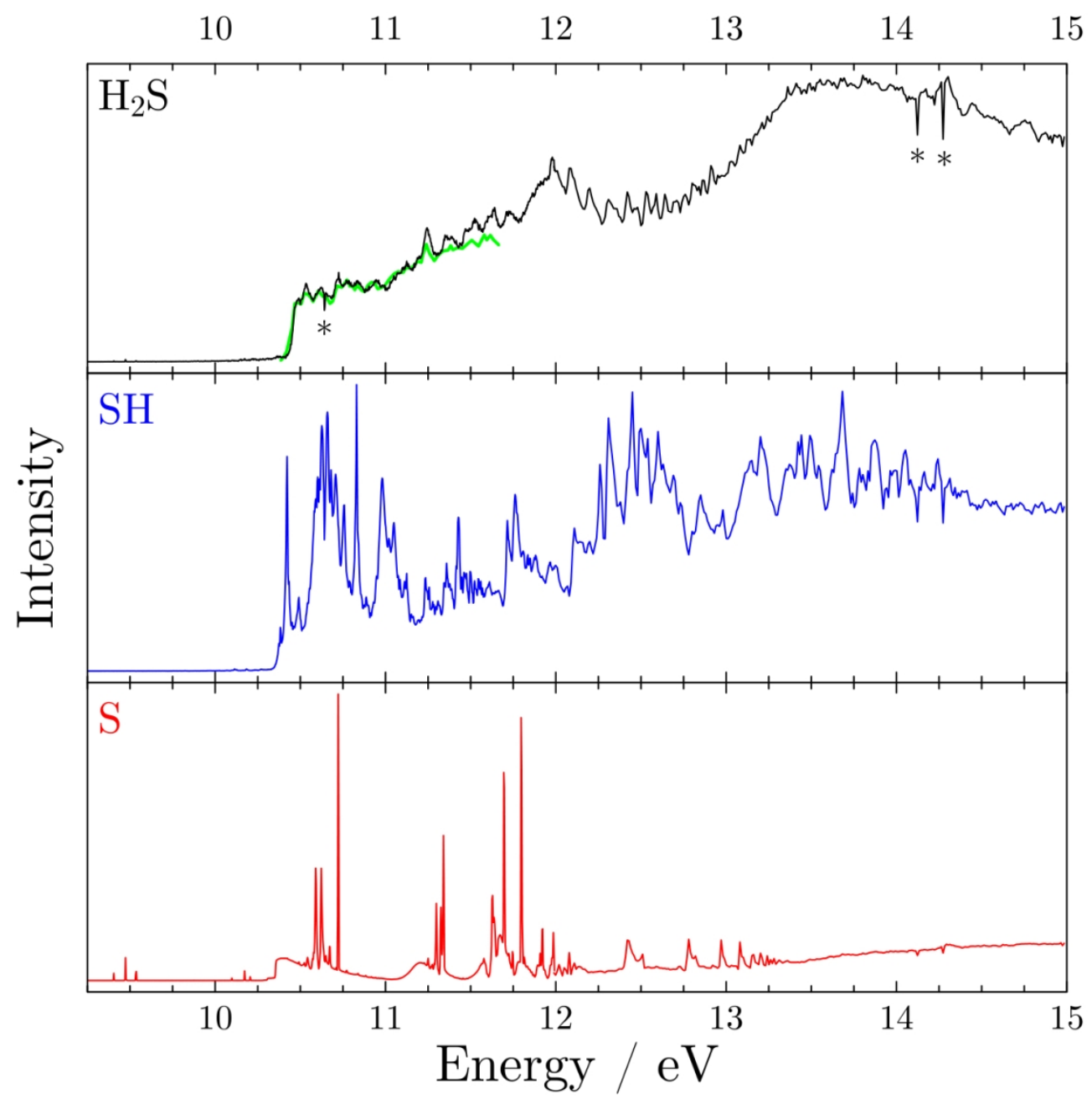

Total photoionization yields of ${ }^{32} \mathrm{~S},{ }^{32} \mathrm{SH}_{1} \mathrm{H}_{2}{ }^{32} \mathrm{~S}$ from 9.7 to $15.0 \mathrm{eV}$. The green inset in the uppermost panel corresponds to the photoionization cross section measured by Watanabe and Jursa. The star signed features in the $\mathrm{H}_{2} \mathrm{~S}$ photoionization yield correspond to Ar absorption lines from the gas filter while the feature at $10.68 \mathrm{eV}$ corresponds to an artefact of the isotopic corrections described in section 2.2. 


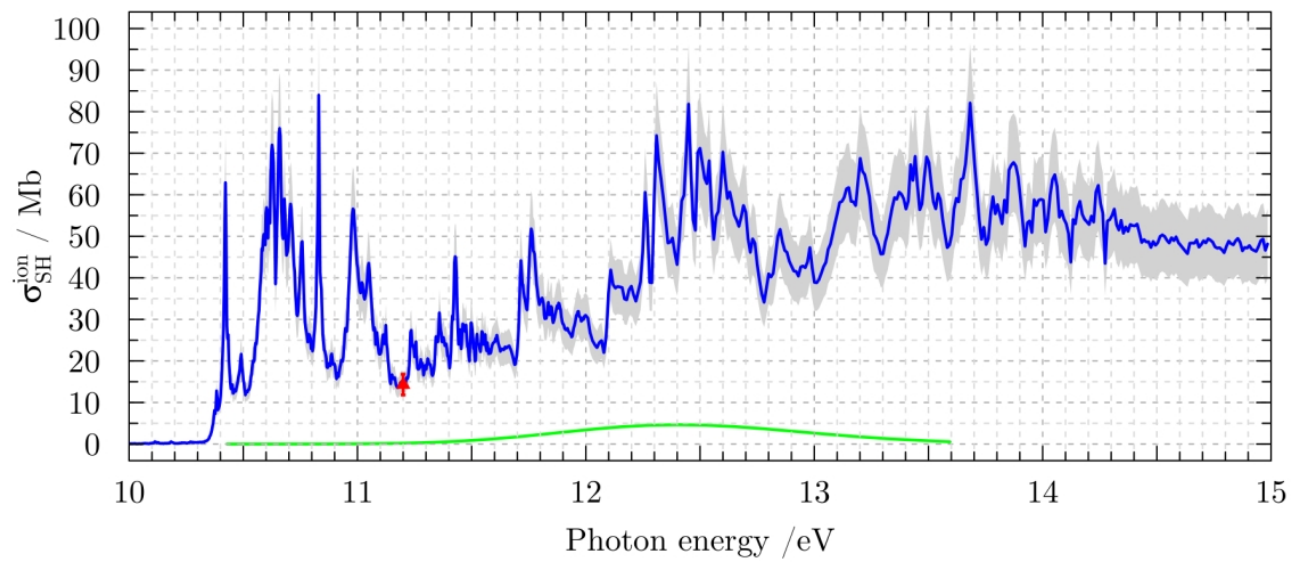

${ }^{32} \mathrm{SH}^{+}$absolute photoionization cross section (in $\mathrm{Mb}=10-18 \mathrm{~cm}^{2}$ ) as a function of the incident photon energy (blue). The red arrow corresponds to the photon energy $(11.2 \mathrm{eV})$ at which the absolute cross section was normalized. The uncertainty of the photoionization yield is presented in gray and is obtained by Monte Carlo uncertainty propagation. In green the arbitrarily simulated SH photoionization cross section from the Leiden database is presented. 


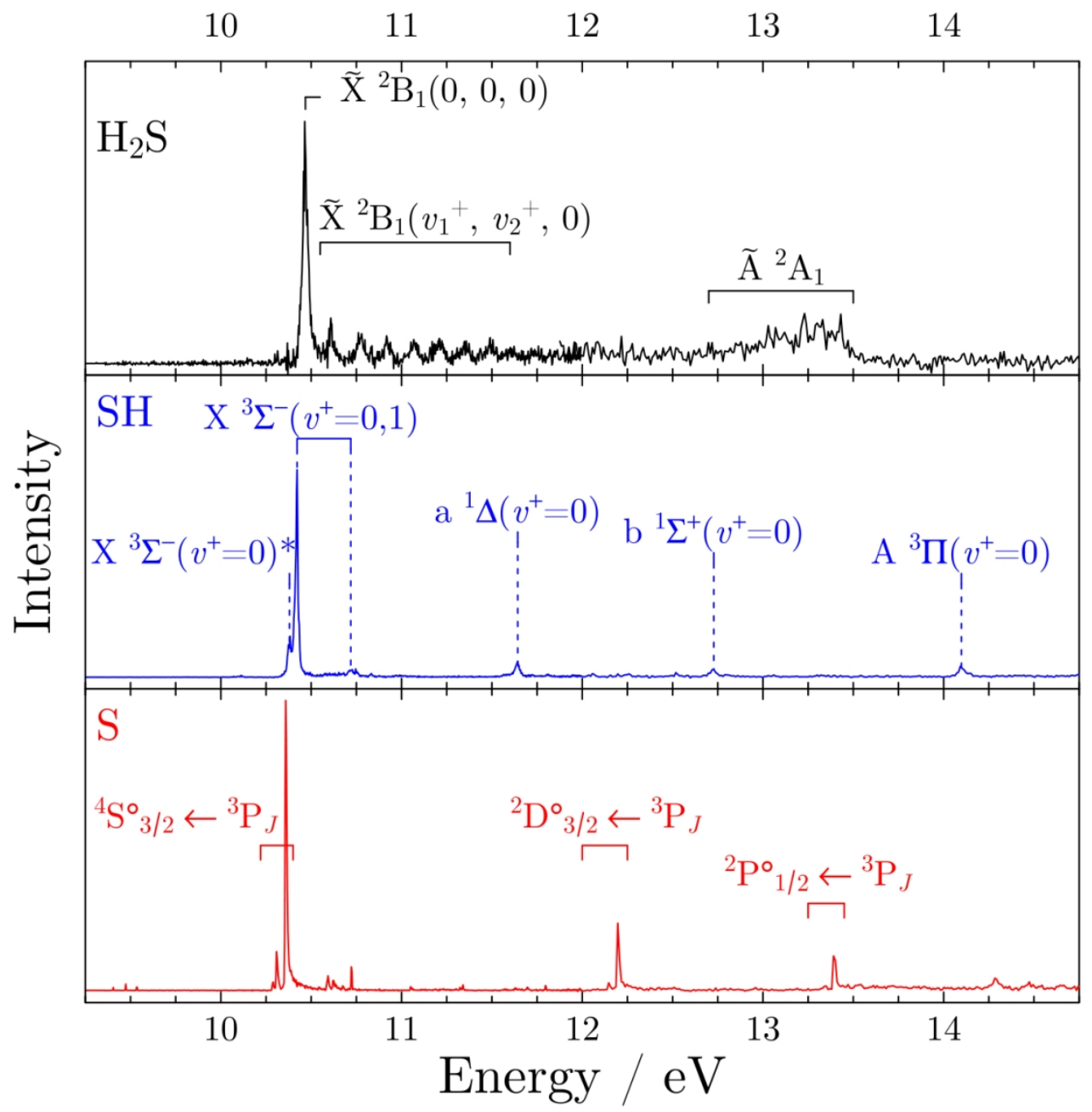

Experimental TPES of $\mathrm{H}_{2} \mathrm{~S}$ (top - black), $\mathrm{SH}$ (middle - blue), and $\mathrm{S}$ (bottom - red). The total energy resolution is $12 \mathrm{meV}$ The assignment marked with an asterisk in the SH spectrum corresponds to the photoionization of the $\Omega=1 / 2$ spin-orbit component of the SH ground state. 


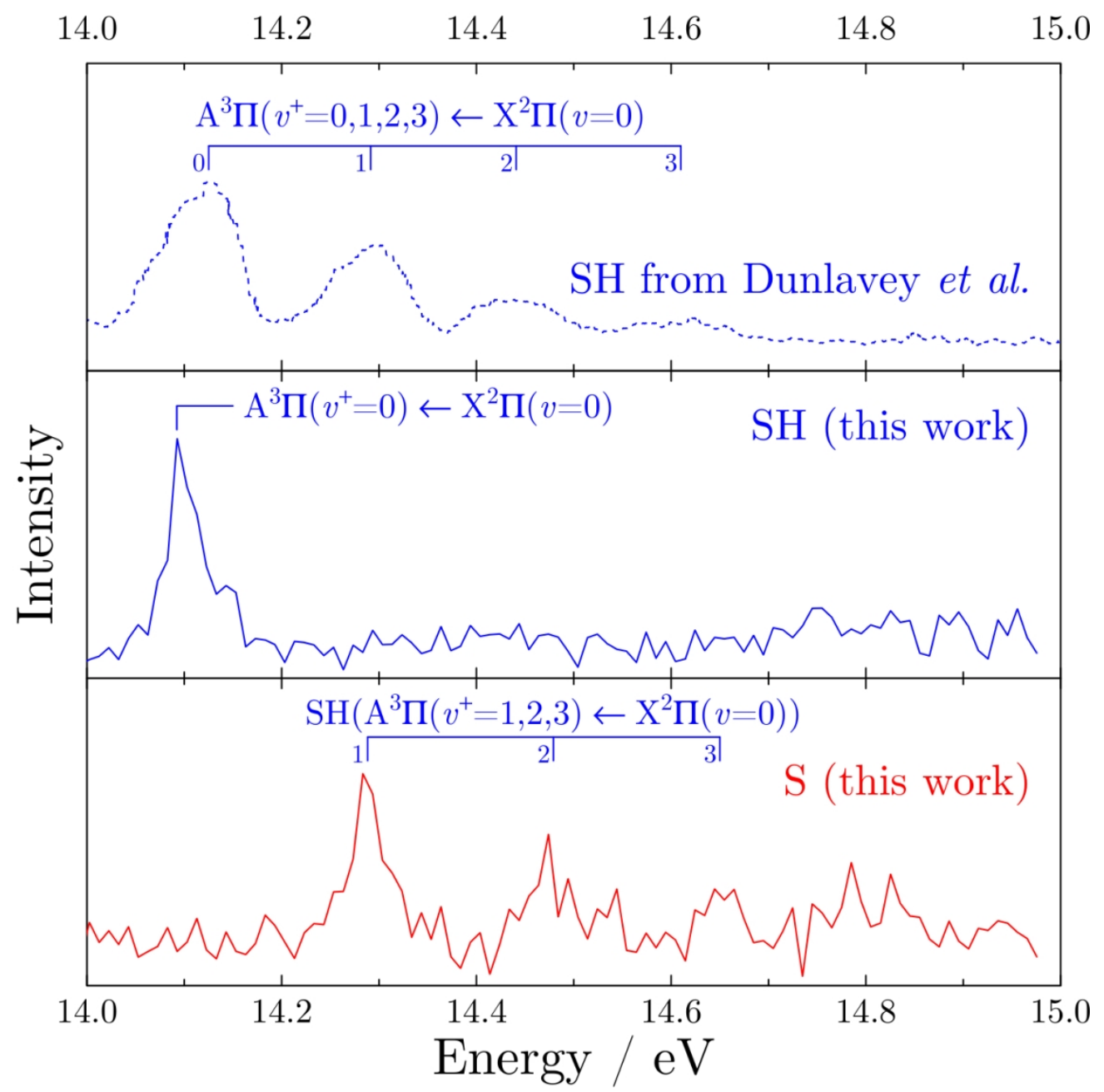

Comparison of the $A^{3} \Pi$ state as observed in the PES from Dunlavey et al. (top panel) and in our TPES of SH (middle panel) and S (bottom panel).

$493 \times 493 \mathrm{~mm}(72 \times 72$ DPI $)$ 


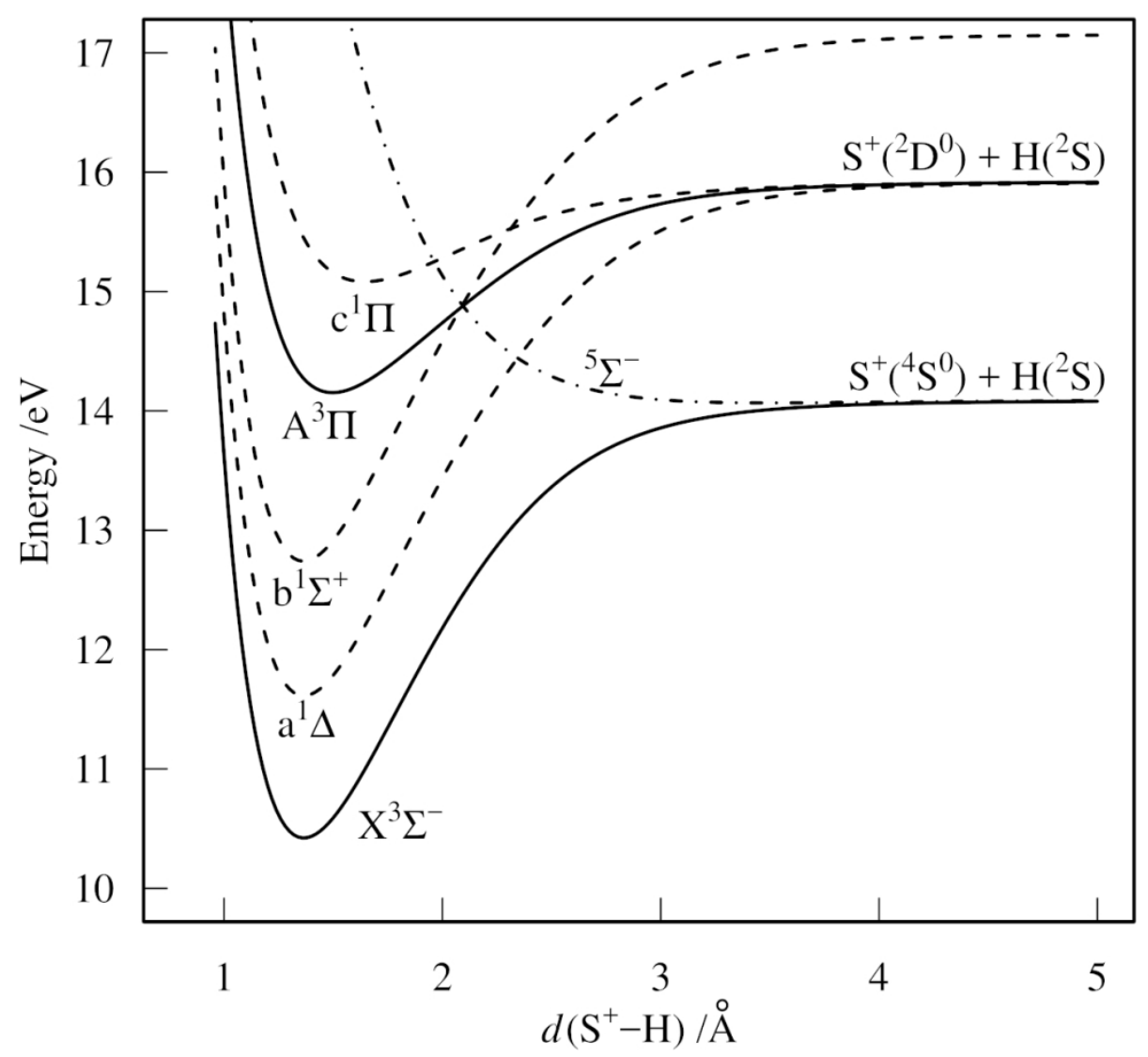

Potential energy curves that are relevant to the $\mathrm{SH}^{+}$cation versus the ground state of neutral $\left.\mathrm{SH}\right)$. Presented are two dissociative thresholds for the formation of $S^{+}$, namely $S^{+}\left({ }^{4} S^{0}\right)$ and $S^{+}\left({ }^{2} D^{0}\right)$, but in the current study we did not proceed to high enough energies to study $S^{+}$formation above the $S^{+}\left({ }^{2} D^{0}\right)+H\left({ }^{2} S\right)$ threshold. 


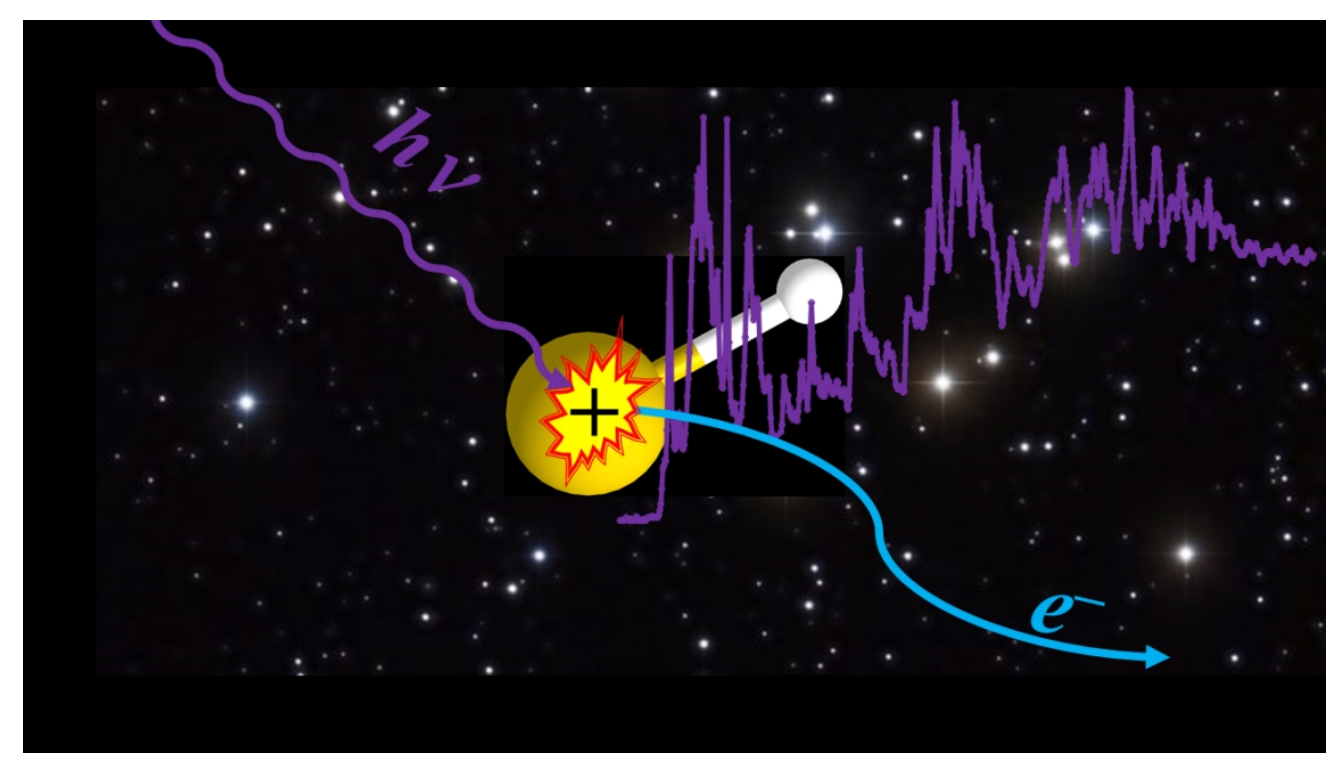

$338 \times 190 \mathrm{~mm}(96 \times 96 \mathrm{DPI})$ 


\section{The Absolute Photoionization Cross Section of the mercapto radical (SH) from Threshold up to $15.0 \mathrm{eV}$ - Supplementary Information}

Helgi Rafn Hrodmarsson, Gustavo A. Garcia, Laurent Nahon

Synchrotron SOLEIL, L'Orme des Merisiers, St Aubin, BP 48, Gif sur Yvette, France Jean-Christophe Loison

Institut des Sciences Moléculaires, UMR 5255 CNRS-Université de Bordeaux, Bât. A12, 351 cours de la Libération, F-33405 Talence Cedex, France

Bérenger Gans

Institut des Sciences Moléculaires d'Orsay (ISMO), CNRS UMR 8214, Univ. Paris-Sud,

Université Paris-Saclay, F-91405 Orsay, France 


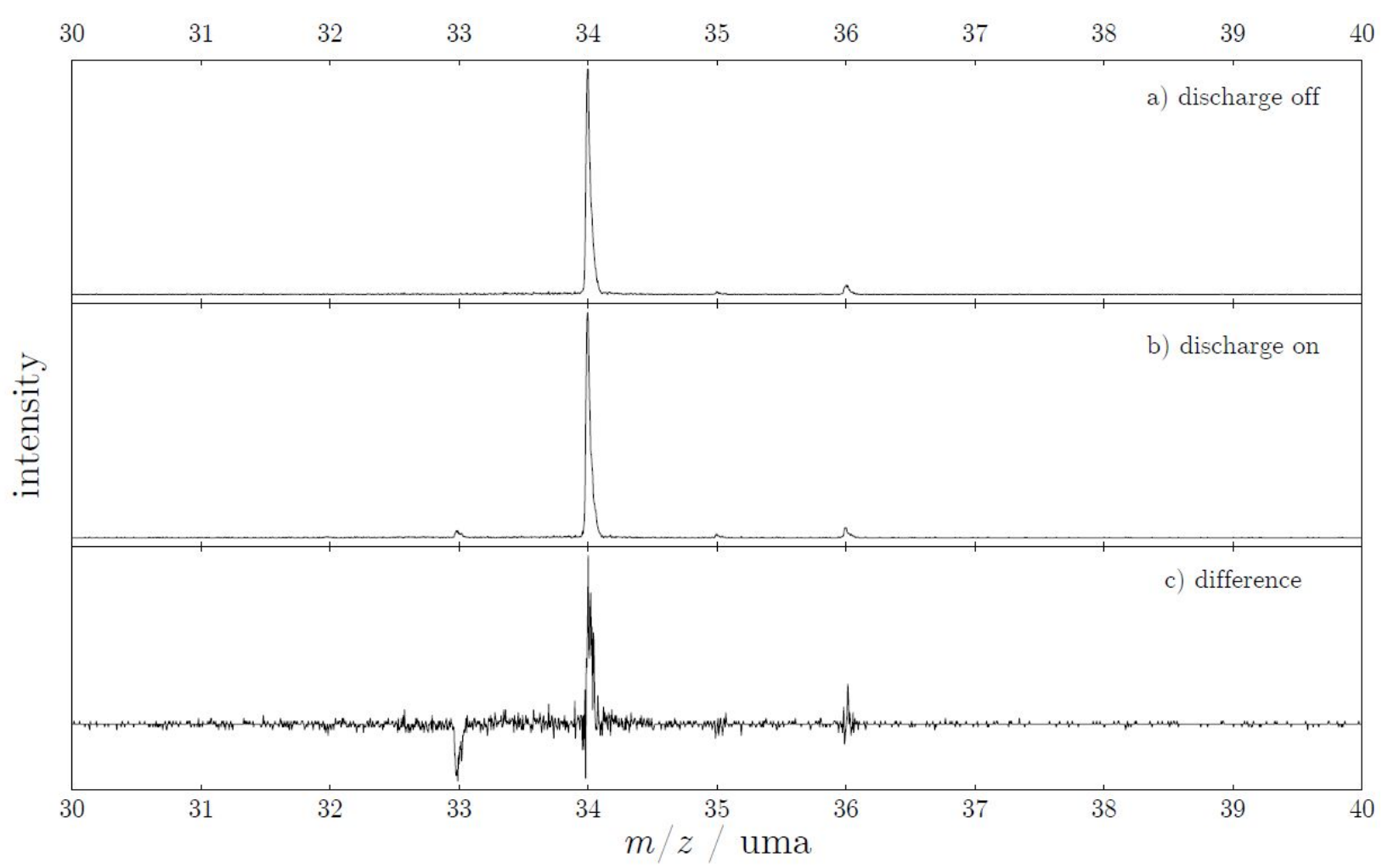

Figure S1. (a) An example of a mass spectrum recorded when the discharge was turned off. (b) The corresponding mass spectrum obtained when the discharge was turned on. (c) The difference spectrum obtained by subtracting (b) from (a). 


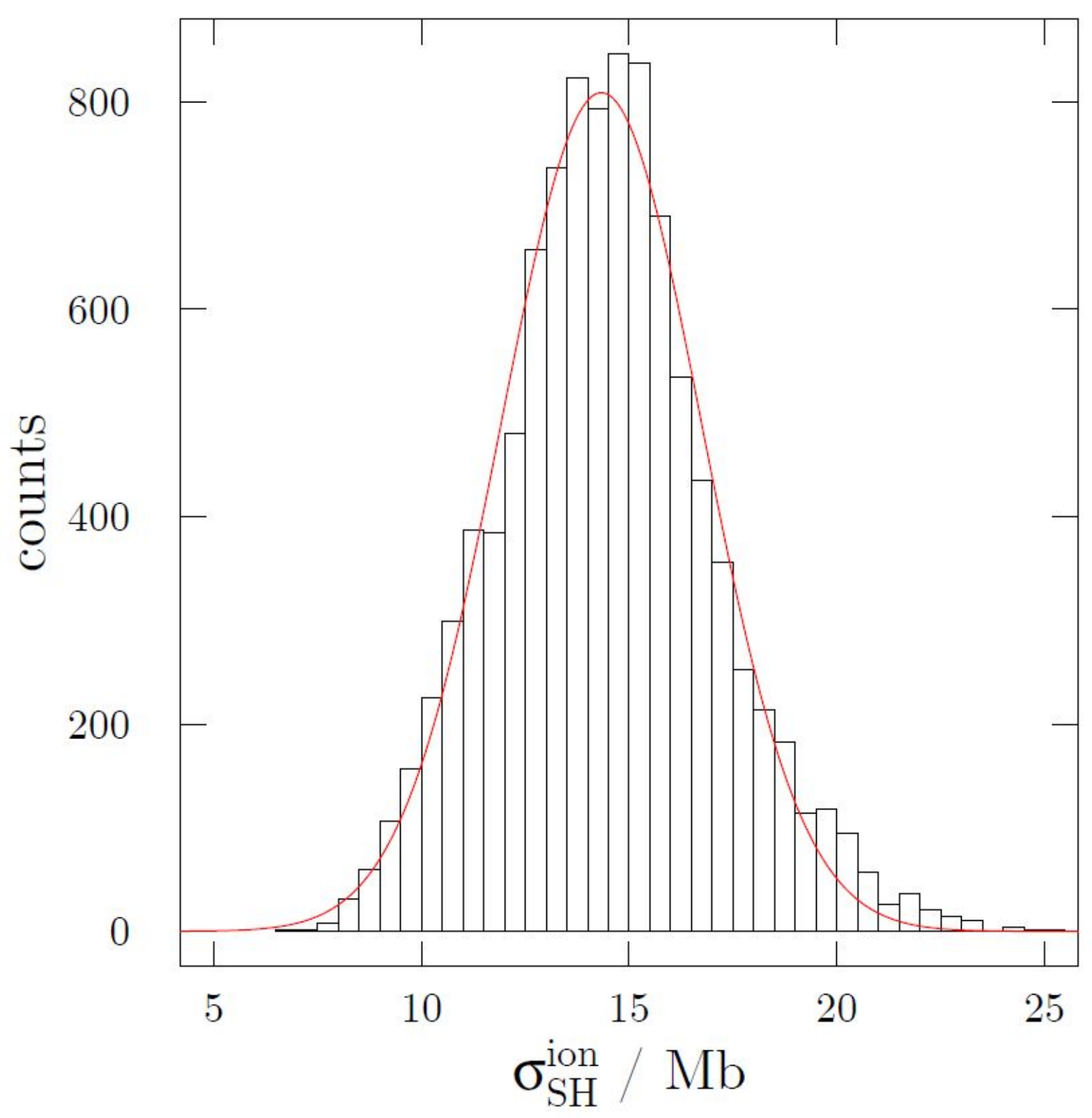

Figure S2. Histogram plot of the distribution of cross section values and associated errors. The distribution is fitted with a Gaussian function to give a mean value for the ionization cross section as $14.3 \pm 4.8 \mathrm{Mb}$. 

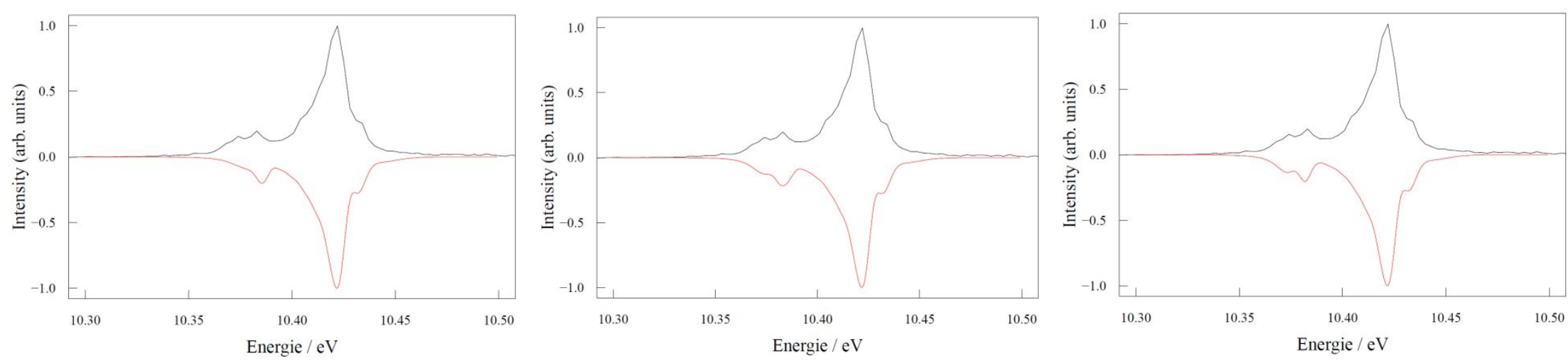

Figure S3. Simulations of the TPES of SH. The left panel displays a simulation with a vibrational population corresponding to $\mathrm{T}_{\text {vib }}=$ $1900 \mathrm{~K}\left(\mathrm{~T}_{\text {spin }}=0.001 \mathrm{~K}\right)$. The middle panel shows a simulation that populates the $\Omega=1 / 2$ spin-orbit component of the $\mathrm{SH}$ ground state using $\mathrm{T}_{\text {spin }}=120 \mathrm{~K}\left(\mathrm{~T}_{\text {vib }}=0.001 \mathrm{~K}\right)$. The simulation is more satisfactory than the previous one which did not populate the $\Omega=1 / 2$ component. A slightly better agreement is obtained in the right panel which was obtained by using $\mathrm{T}_{\text {spin }}=100 \mathrm{~K} \& \mathrm{~T}_{\text {vib }}=1500 \mathrm{~K}$.

The rotational contour of the origin band was calculated using molecular constants from Ramsey ${ }^{1}$ for $\mathrm{SH}$ and $\mathrm{Brown} \& \mathrm{Muller}^{2}$ for $\mathrm{SH}^{+}$. The rotation was supposedly thermalized and thus the rotational temperature was fixed at $300 \mathrm{~K}$. The intensities of the rotational branches were manually adjusted to reproduce the strong feature (right side of the origin band) corresponding to the ${ }^{3} \Sigma^{-}\left(v^{+}=0\right) \leftarrow{ }^{2} \Pi_{3 / 2}\left(v^{\prime \prime}=0\right)$ transition. A good match was found using (1:1:0.3:0.4:0.1) for the intensity weights for the $\Delta \mathrm{N}=-2,-1,0,1,2$ rotational branches in Hunds case $b$ notation. The same weights were used for the transitions involving the two spin orbit components of the neutral. To reproduce the left side of the origin band, only the spin temperature and the vibrational temperature were adjusted. 
Table S1. Energies of the TPES peaks for the vibrational bands of $\left(v_{1}^{+}, v_{2}{ }^{+}, 0\right)$ levels of the $\mathrm{H}_{2} \mathrm{~S}^{+}\left(\tilde{\mathrm{X}}^{2}\right.$ $\left.\mathrm{B}_{1}\right)$ state observed in the upper panel of Figure 4.

\begin{tabular}{|c|c|c|c|c|c|}
\hline $\begin{array}{l}\text { Vibrational } \\
\text { level }\end{array}$ & $\begin{array}{l}\text { Energy } \\
(\mathrm{eV})-\text { our } \\
\text { values }\end{array}$ & $\begin{array}{l}\text { Energy } \\
(\mathrm{eV}) \\
\text { Hochlaf et } \\
a .^{3}\end{array}$ & $\begin{array}{l}\text { Vibrational } \\
\text { level }\end{array}$ & $\begin{array}{l}\text { Energy (eV) } \\
\text { - our values }\end{array}$ & $\begin{array}{l}\text { Energy } \\
(\mathrm{eV}) \\
\text { Hochlaf } \\
\text { et al. }{ }^{3}\end{array}$ \\
\hline$(0,0,0)$ & 10.468 & 10.468 & $(1,4,0)$ & 11.330 & 11.332 \\
\hline$(0,1,0)$ & 10.610 & 10.612 & $(2,2,0)$ & 11.351 & 11.359 \\
\hline$(0,2,0)$ & - & 10.754 & $(3,0,0)$ & - & 11.386 \\
\hline$(1,0,0)$ & 10.773 & 10.7778 & $(0,7,0)$ & 11.459 & 11.447 \\
\hline$(0,3,0)$ & 10.88 & 10.899 & $(1,5,0)$ & - & 11.467 \\
\hline$(1,1,0)$ & 10.923 & 10.918 & $(2,3,0)$ & 11.485 & 11.494 \\
\hline$(0,4,0)$ & - & 11.034 & $(3,1,0)$ & 11.512 & 11.518 \\
\hline$(1,2,0)$ & - & 11.058 & $(0,8,0)$ & 11.572 & 11.575 \\
\hline$(2,0,0)$ & 11.071 & 11.077 & $(1,6,0)$ & - & 11.604 \\
\hline$(0,5,0)$ & 11.171 & 11.173 & $(2,4,0)$ & 11.624 & 11.629 \\
\hline$(1,3,0)$ & 11.212 & 11.216 & $(3,2,0)$ & 11.659 & 11.668 \\
\hline$(2,1,0)$ & 11.239 & 11.224 & $(0,9,0)$ & - & 11.704 \\
\hline$(0,6,0)$ & 11.304 & 11.310 & $(1,7,0)$ & 11.737 & 11.739 \\
\hline
\end{tabular}


Table S2. Compilation of the direct ionization peaks we observe in the TPES of atomic sulfur and comparisons with values from the NIST atomic spectra database.

\begin{tabular}{|l|l|l|l|}
\hline Initial state & Final (ion) state & Measured values & Values from NIST \\
& & (this work) & \\
\hline $3 s^{2} 3 p^{4}{ }^{3} \mathrm{P}_{0}$ & $3 s^{2} 3 p^{3}\left[{ }^{4} \mathrm{~S}_{3 / 2}^{\circ}\right]$ & $10.288 \pm 0.002$ & 10.289 \\
\hline $3 s^{2} 3 p^{4}{ }^{3} \mathrm{P}_{1}$ & $3 s^{2} 3 p^{3}\left[{ }^{4} \mathrm{~S}_{3 / 2}^{\circ}\right]$ & $10.309 \pm 0.002$ & 10.311 \\
\hline $3 s^{2} 3 p^{4}{ }^{3} \mathrm{P}_{2}$ & $3 s^{2} 3 p^{3}\left[{ }^{4} \mathrm{~S}_{3 / 2}^{\circ}\right]$ & $10.360 \pm 0.002$ & 10.360 \\
\hline $3 s^{2} 3 p^{4}{ }^{1} \mathrm{D}_{2}$ & $3 s^{2} 3 p^{3}\left[{ }^{2} \mathrm{D}_{3 / 2}^{\circ}\right]$ & $11.051 \pm 0.002$ & 11.056 \\
\hline $3 s^{2} 3 p^{4}{ }^{3} \mathrm{P}_{1}$ & $3 s^{2} 3 p^{3}\left[{ }^{2} \mathrm{D}_{3 / 2}^{\circ}\right]$ & $12.149 \pm 0.006$ & 12.153 \\
\hline $3 s^{2} 3 p^{4}{ }^{3} \mathrm{P}_{2}$ & $3 s^{2} 3 p^{3}\left[{ }^{2} \mathrm{D}_{3 / 2}^{\circ}\right]$ & $12.199 \pm 0.006$ & 12.202 \\
\hline $3 s^{2} 3 p^{4}{ }^{3} \mathrm{P}_{2}$ & $3 s^{2} 3 p^{3}\left[{ }^{2} \mathrm{P}_{1 / 2}^{\circ}\right]$ & $13.393 \pm 0.006$ & 13.401 \\
\hline
\end{tabular}




\section{References}

1. D. A. Ramsay, J. Chem. Phys., 1952, 20, 1920-1927.

2. J. M. Brown and H. S. P. Muller, J. Mol. Spectrosc., 2009, 255, 68-71.

3. M. Hochlaf, K. M. Weitzel and C. Y. Ng, J. Chem. Phys., 2004, 120, 6944-6956.

4. A. Kramida, Y. Ralchenko, J. Reader and N. A. Team, National Institute of Standards and Technology, Gaithersburg, MD2018. 


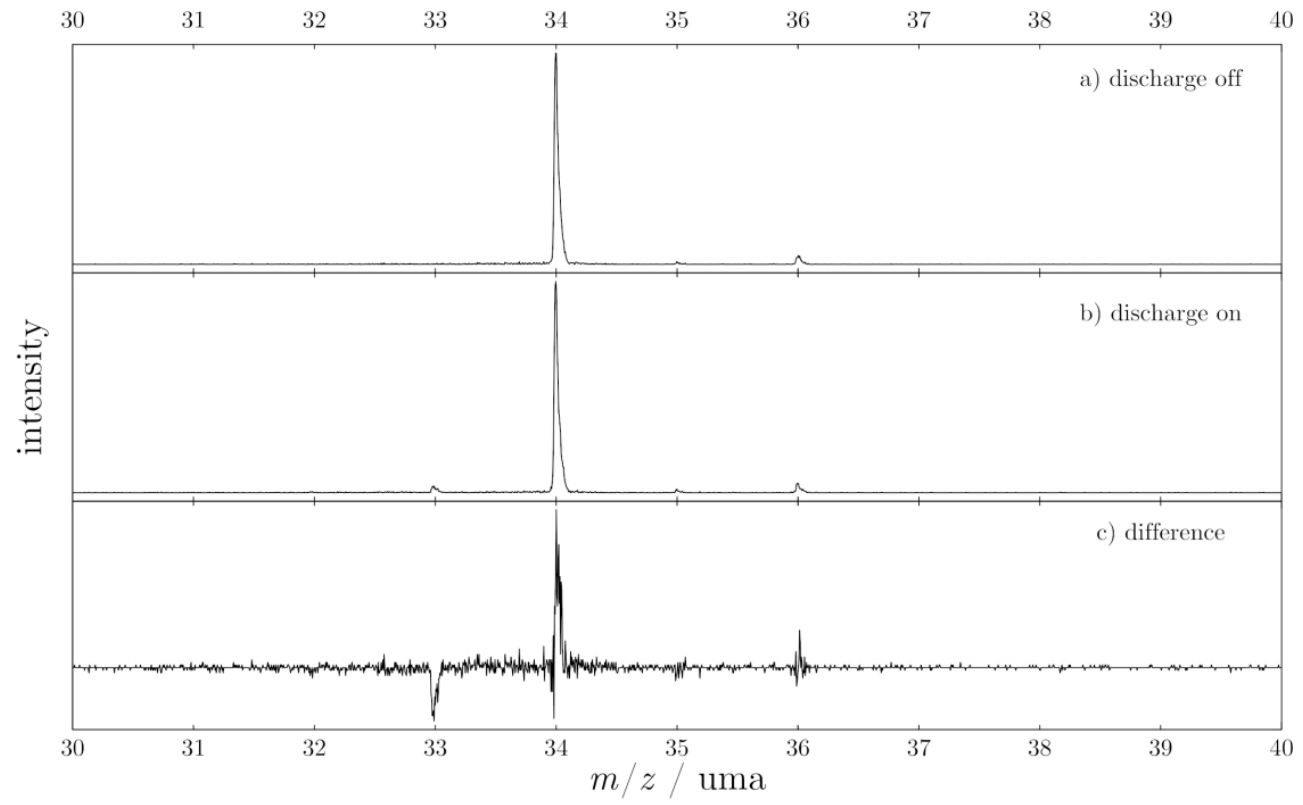

(a) An example of a mass spectrum recorded when the discharge was turned off. (b) The corresponding mass spectrum obtained when the discharge was turned on. (c) The difference spectrum obtained by subtracting (b) from (a).

$845 \times 528 \mathrm{~mm}(72 \times 72 \mathrm{DPI})$ 


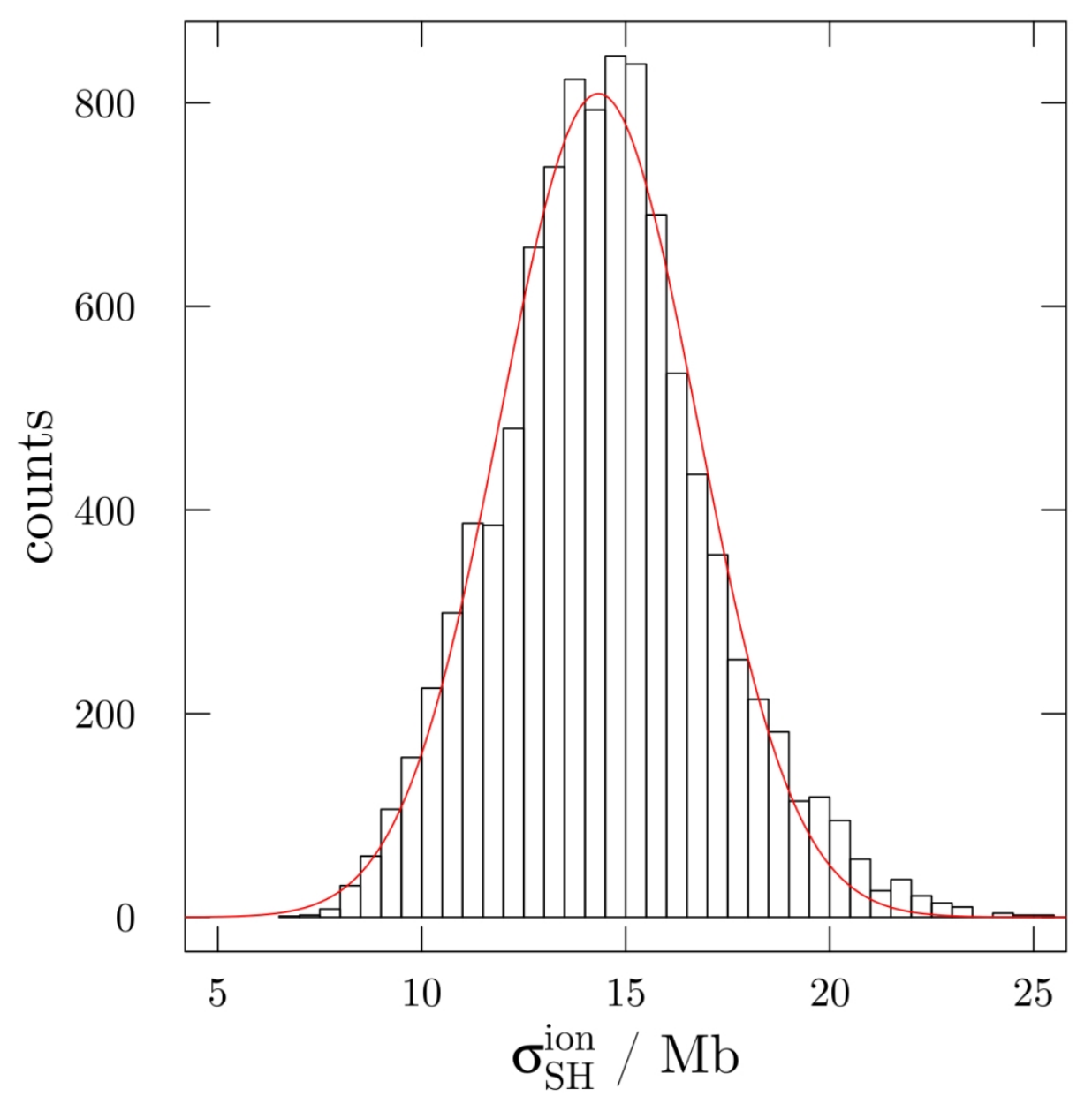

Histogram plot of the distribution of cross section values and associated errors. The distribution is fitted with a Gaussian function to give a mean value for the ionization cross section as $14.3 \pm 4.8 \mathrm{Mb}$. 


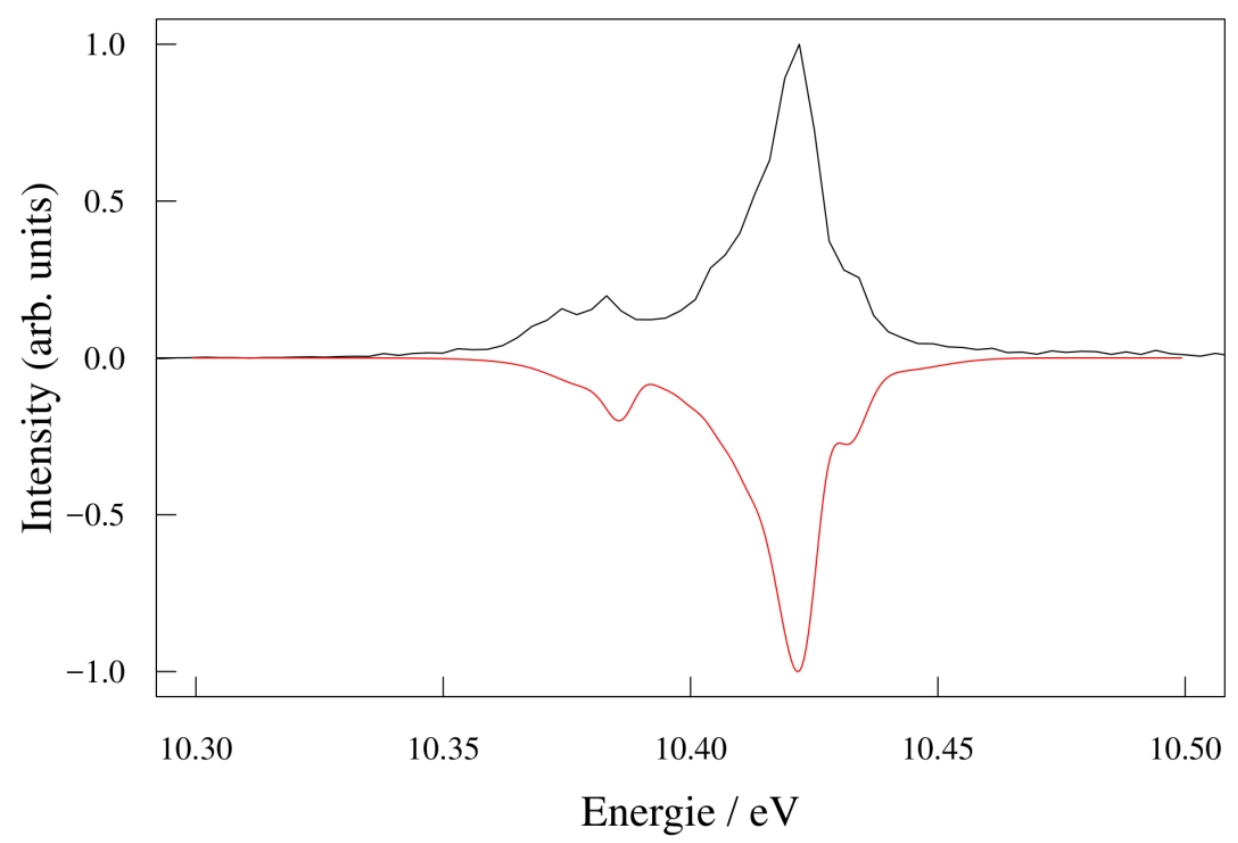

Simulations of the TPES of SH. The left panel displays a simulation with a vibrational population corresponding to $\mathrm{T}_{\mathrm{vib}}=1900 \mathrm{~K}\left(\mathrm{~T}_{\text {spin }}=0.001 \mathrm{~K}\right)$. The middle panel shows a simulation that populates the $\Omega$ $=1 / 2$ spin-orbit component of the $\mathrm{SH}$ ground state using $\mathrm{T}_{\text {spin }}=120 \mathrm{~K}\left(\mathrm{~T}_{\mathrm{vib}}=0.001 \mathrm{~K}\right)$. The simulation is more satisfactory than the previous one which did not populate the $\Omega=1 / 2$ component. A slightly better agreement is obtained in the right panel which was obtained by using $T_{\text {spin }}=100 \mathrm{~K} \& \mathrm{~T}_{\text {vib }}=1500 \mathrm{~K}$. 


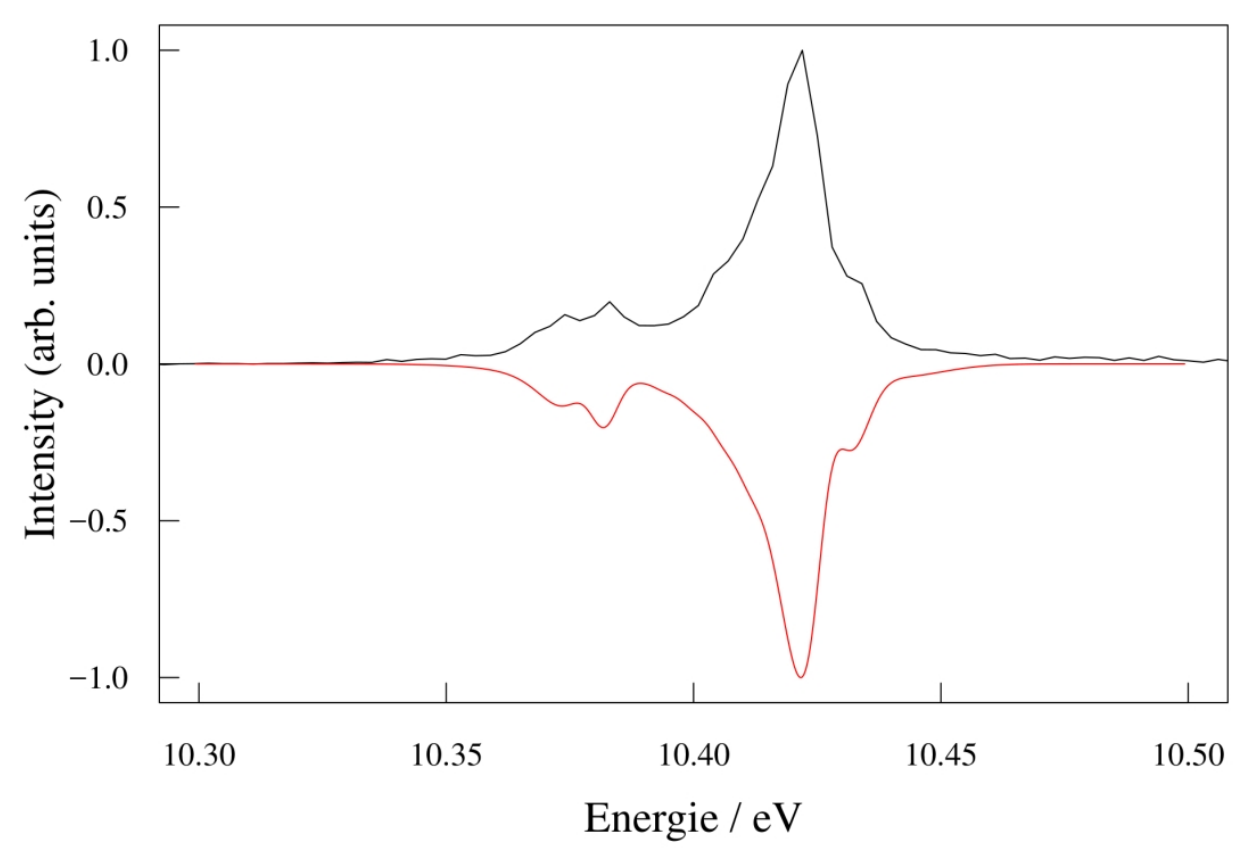

$705 \times 493 \mathrm{~mm}(72 \times 72$ DPI $)$ 


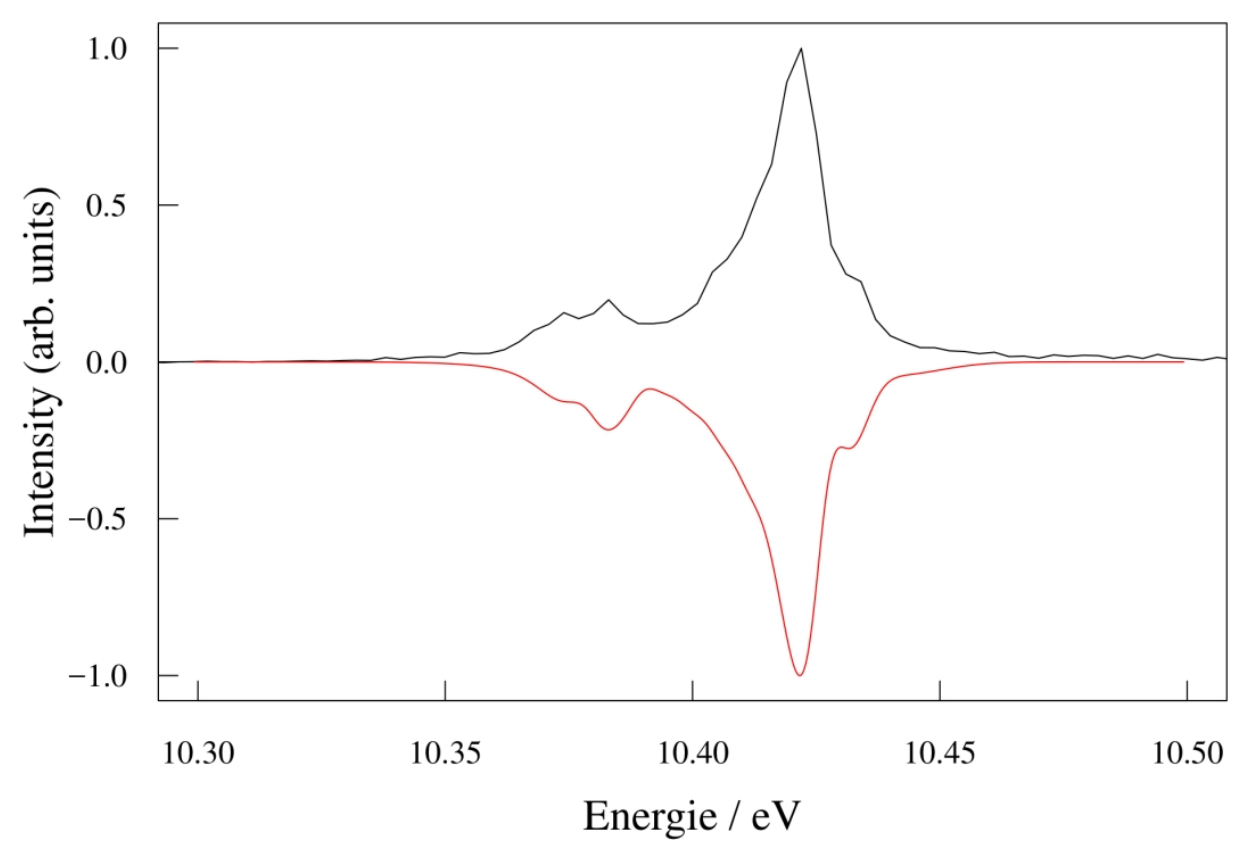

$705 \times 493 \mathrm{~mm}(72 \times 72$ DPI $)$ 